\title{
AN ANALYSIS OF THERMAL TRACK BUCKLING IN THE LATERAL PLANE
}

\author{
Arnold D. Kerr \\ Princeton University \\ Department of Civil Engineering \\ Princeton NJ 08540
}

SEPTEMBER 1976

INTERIM REPORT

DOCUMENT IS AVAILABLE TO THE U.S. PUBLIC

THAOUGH THE NATIONAL TECHNICAL

INFORMATION SERVICE, SPRINGFIELD,

VIRGINIA 22161

$$
\text { Prepared for }
$$

U,S, DEPARTMENT OF TRANSPORTATION FEDERAL RAILROAD ADMINISTRATION Office of Research and Development Washington DC 20590

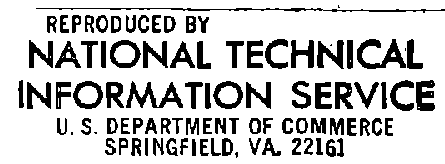




\section{NOTICE}

This document is disseminated under the sponsorship of the Department of Transportation in the interest of information exchange. The United States Government assumes no liability for its contents or use thereof.

\section{NOTICE}

The United States Government does not endorse products or manufacturers. Trade or manufacturers' names appear herein solely because they are considered essential to the object of this report. 
Technical Report Documentotion Page

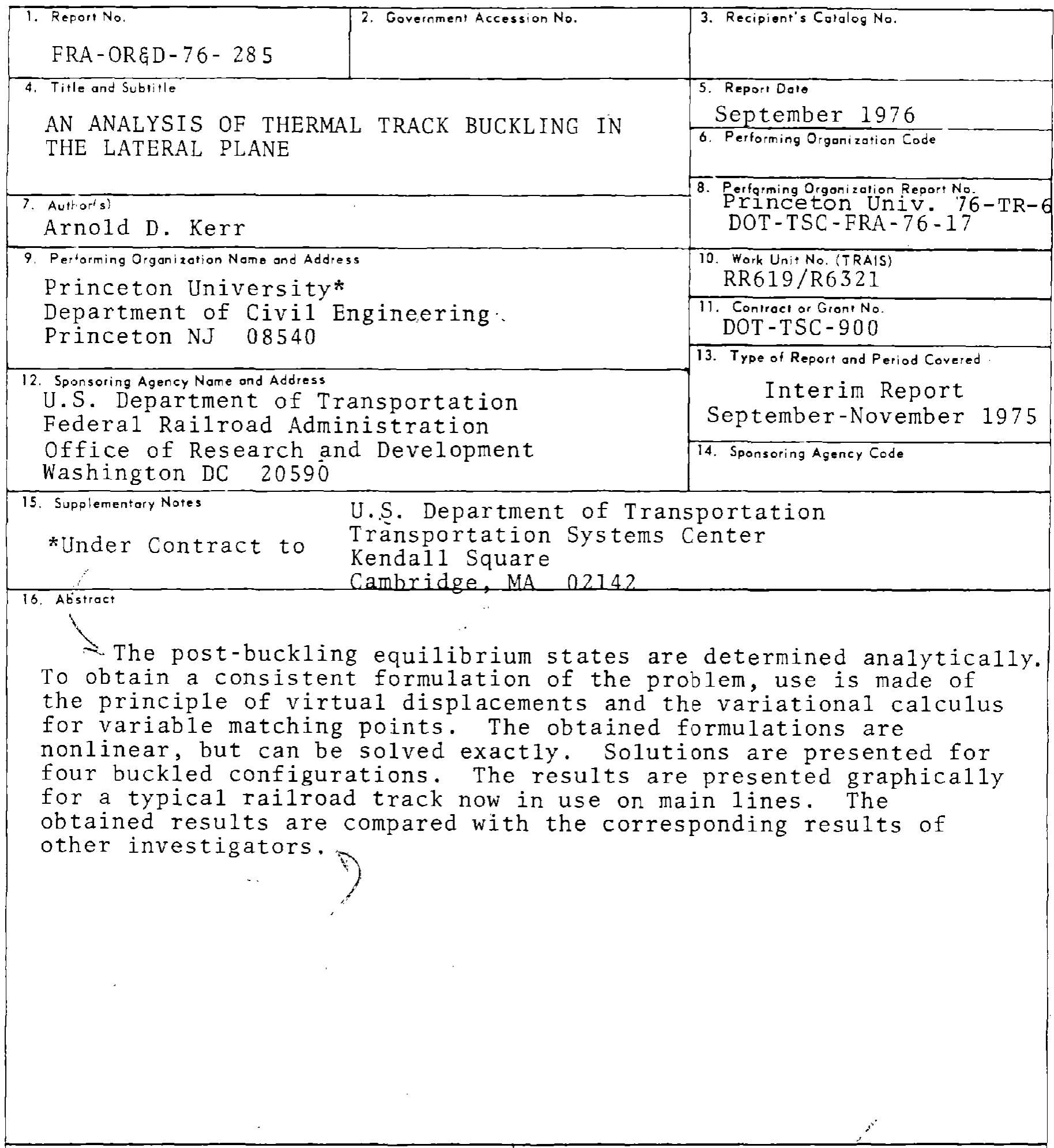

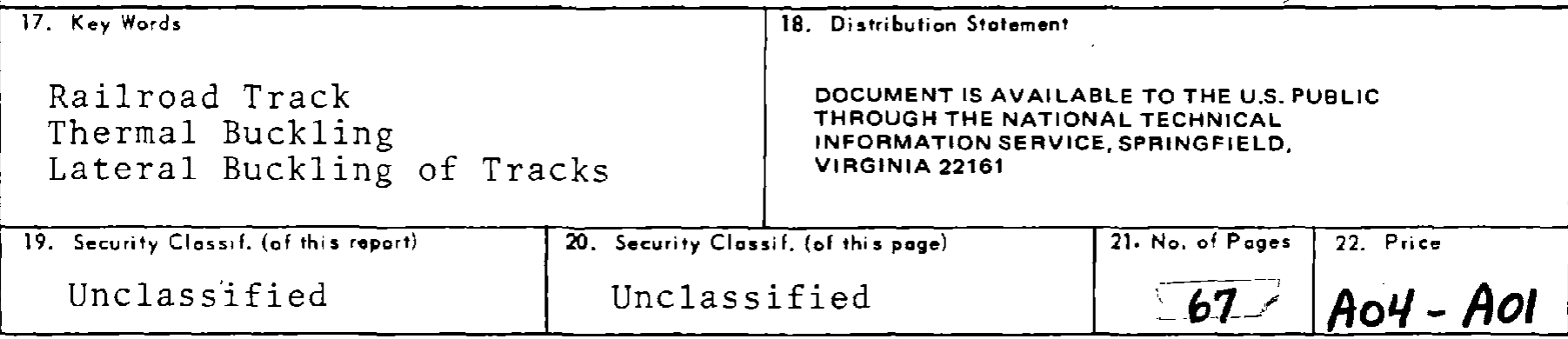

Form DOT F 1700.7 (8-72)

Reproduction of completed page authorized 
, 


\section{PREFACE}

This report is a partial result of a research effort whose aim is to form a basis for the rational design, construction and maintenance of railroad tracks. This research program is sponsored by the Federal Railroad Administration, Office of Research \& Development, with the Transportation Systems Center as program manager. The present rejort was prepared as part of the contract DOT-TSC-900 with Dr. Arnold D. Kerr as Project Director and Dr. Andrew Kish, Transportation Systems Center, as technical monitor.

The author wishes to thank Dr. Allan Zarembski for performing the numerical evaluations presented in this report. Thanks are also due to Dr. Andrew Kish TSC/DOT and Dr. R. Michael McCafferty FRA/DOT for reading and commenting on the content of the report. 


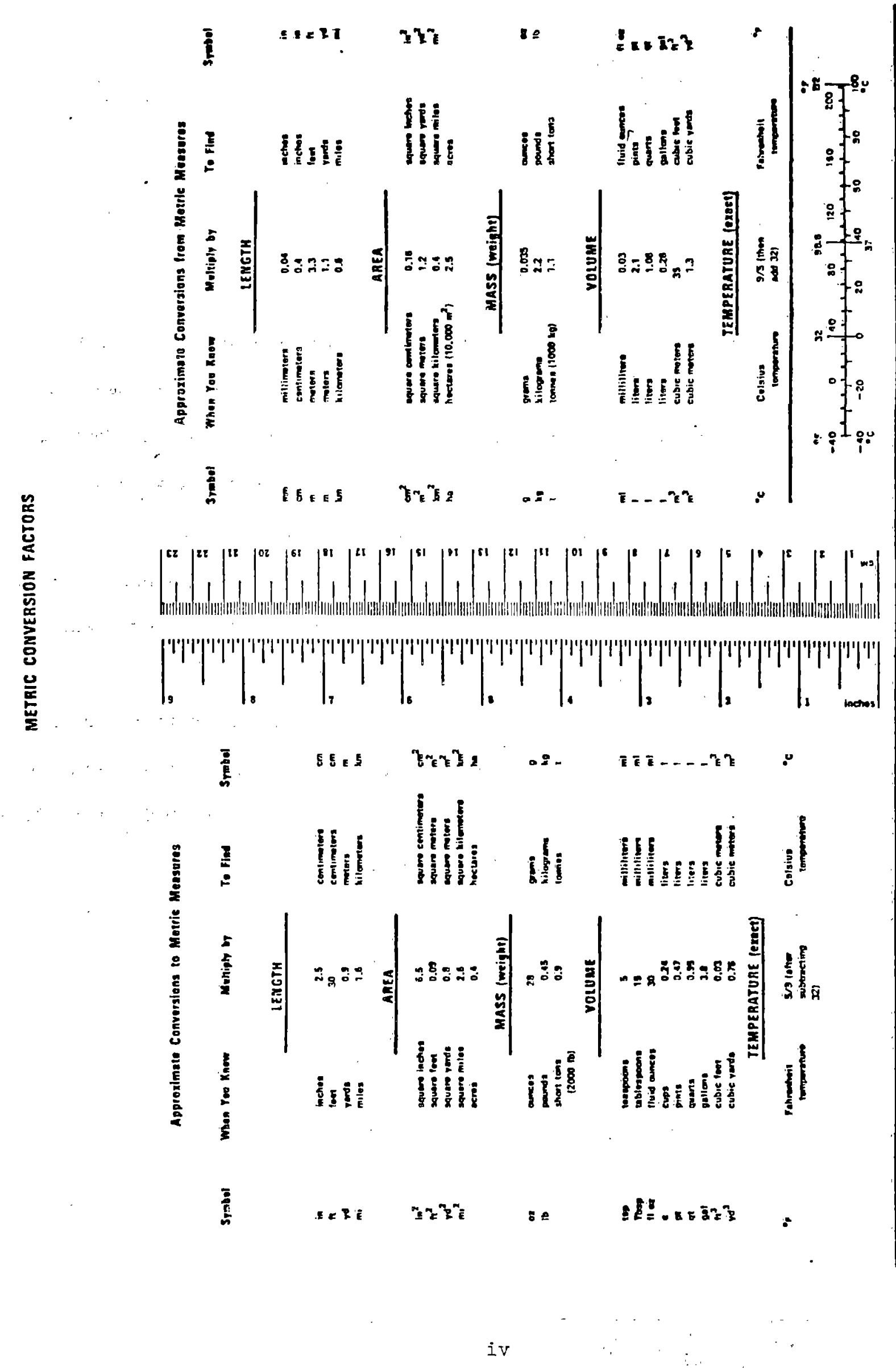




\section{EXECUTIVE SUMMARY}

A uniform temperature increase, $T_{0}$ in the rails of a straight welded track induces in the two rails, due to constrained thermai expansions, an axial compression force

$$
\mathrm{N}_{\mathrm{t}}=\mathrm{E} \cdot \mathrm{A} \propto \mathrm{T}_{\mathrm{O}}
$$

For example, for a track with 115 lb/yard rails, a temperature increase of $30^{\circ} \mathrm{C}\left(54^{\circ} \mathrm{F}\right)$ induces in the rails an axial compression force of 96 metric tonnes.

For sufficiently large compression forces the track may buckle out. According to observations in the field and in track bucking tests (Fig. 1), continuously welded tracks buckle usually in the lateral plane. The observed buckling mode of a long straight track consists of a buckled region which exhibits large lateral deformations and the adjoining track regions which appear to deform only axially.

Analyses for the determination of railroad track buckling, caused by a raise in temperature, have been conducted in the past several decades by many investigators throughout the World. A critical survey of these analyses, and of the related test results, were recentiy presented by A.D. Kerr (Reference [1]). This survey revealed that the majority of the published analyses are not suitable for the determination of the thermal track buckling problem, because they are based on formulations which do not describe correctly the track buckling phenomenon. Those few analyses which are conceptually on the right path 
exhibit analytical shortcomings with an unknown effect on the final results.

The purpose of this report is to present a mechanically reasonable and mathematically consistent analysis for the thermal buckling of tracks in the lateral plane.

The presented analyses are valid for tracks which use cut-spike fasteners with a negligible rotational resistance; thus, for the majority of railroad tracks in the USA.

The "safe temperature increase" above the neutral (i.e. installation) temperature is defined as follows: The track analysis yields equilibrium branches of the type shown in figure. From this figure (and an additional stability analysis), it follows that for a temperature increase $\mathrm{T}_{\mathrm{C}}$ smaller than $\mathrm{T}_{\mathrm{L}}$ there exists only one stable equilibrium state, namely

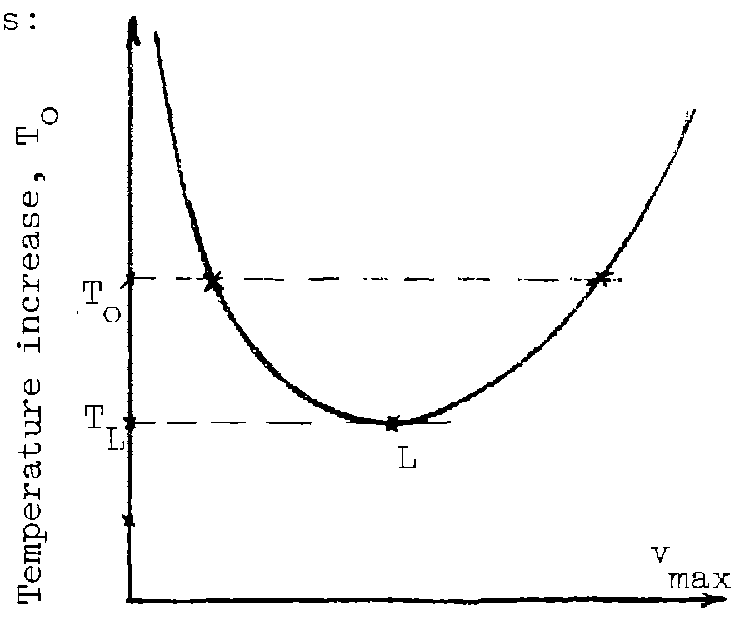
the straight one. However, for $\mathrm{T}_{0}$ larger than $\mathrm{T}_{\mathrm{L}}$, there exist three equilibrium states. Thus, for $\mathrm{T}_{0}$ larger than $\mathrm{T}_{\mathrm{L}}$, also deformed (i.e. buckled) states of equilibrium do exist. Therefore the range of safe temperature increases is $0<T_{0}<T_{L}$ Namely; the anticipated rail temperature increase above neutral should be smaller than the value $\mathrm{T}_{\mathrm{L}}$ for a track under consideration. 
Once $\mathrm{T}_{\mathrm{L}}$ is determined analytically, the installation temperature of the rails may be determined as

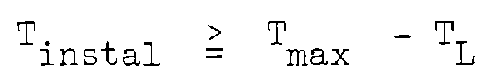

where $\mathrm{T}_{\max }$ is the highest anticipated rail temperature in a particular geographical region.

The analytical part of this paper is devoted to the determination of the equilibrium branches for heated tracks, and of the corresponding $\mathrm{T}_{\mathrm{L}}$ values. Since the majority of engineers will not be familiar with the presented analyses, the obtained results are being numerically evaluated for a variety of track parameters. The results of this parametric study will be presented as graphs in a manual-type report which is currently in preparation under contract DOT-TSC-1149. 
TABLE OF CONTENTS

$\underline{\text { Page }}$

I. INTRODUCTION . . . . . . . . . . . . . . . . . . I

2. THE THERMAL TRACK BUCKLING PHENOMENON . . . . . . . . . 3

3. ANALYTICAL PRELIMINARIES . . . . . . . . . . . . . 5

4. ANALYSES OF TRACK BUCKLInG . . . . . . . . . . . . . . II

4.1 Analysis of Symmetrical Deformation Shape I . . . . I2

4.2 Analysis of Antisymmetrical Deformation Shape II . . 28

4.3 Analysis of Symmetrical Deformation Shape III . . . 31

4.4 Analysis of Antisymmetrical Deformation Shape IV . . 38

4.5 Remarks on Obtained Results ........... . 41

5. COMPARISON WITH RESULTS OF OTHER INVESTIGATORS . . . . . 42

6. CONCLUSIONS AND RECOMMENDATIONS ............. . . 51 REFERENCES . . . . . . . . . . . . . . . . . 5h APPENDIX. REPORT OF INVENTIONS . . . . . . . . . . . 57 
• 
Figure

1. Buckled Tracks . . . . . . . . . . . . . . . . . 2

2. Distribution of Axial Compression Forces Before and After Buckling. . . . . . . . . . . . . . . . . 4

3. Lateral and Axial Track Resistances . . . . . . . . 6

4. Notation and Convention Used in Analysis. . . . . . . . . II

5. Lateral Deflection Shapes... . . . . . . . . . .13

6. Relations at the Variable Matching Point $\mathrm{x}=$ 2. . . . . .19

7. Mechanical Interpretation of a Derived Condition. . . . .19

8. Comparison of Post-Buckling. Equilibrium Branches and the Corresponding Axial Forces $\tilde{\mathbb{N}}_{t}$, for Shapes I to IV .27

9. Comparison of Post-Buckling Equilibrium Branches for Shape I by Martinet, Mishchenko, Numata, and Kerr. . . .46

10. Comparison of Post-Buckling Equilibrium Branches for Shape IJ by Martinet, Mishchenko, Numata, and Kerr . . .47

11. Comparison of Post-Buckling Equilibrium Branches and $\tilde{\mathbb{N}}_{t}$-curves for Shape III by Martinet, Numata, and Kerr .48

12. Comparison of Post-Buckling Equilibrium Branches and $\tilde{\mathrm{N}}_{\mathrm{t}}$-curves for Shape IV by Numata and Kerr . . . . . . .49

IIST OF TABLES

Table

1. Calculated Track Data - Shape I. . . . . . . . . . . .28

2. Calculated Track Data - Shape II. . . . . . . . . . .31

3. Calculated Track Data - Shape III . . . . . . . . .38

4. Calculated Track Data - Shape IV . . . . . . . . . 40

5. Values of Parameters................ 45 


\section{IIST OF SYMBOLS}

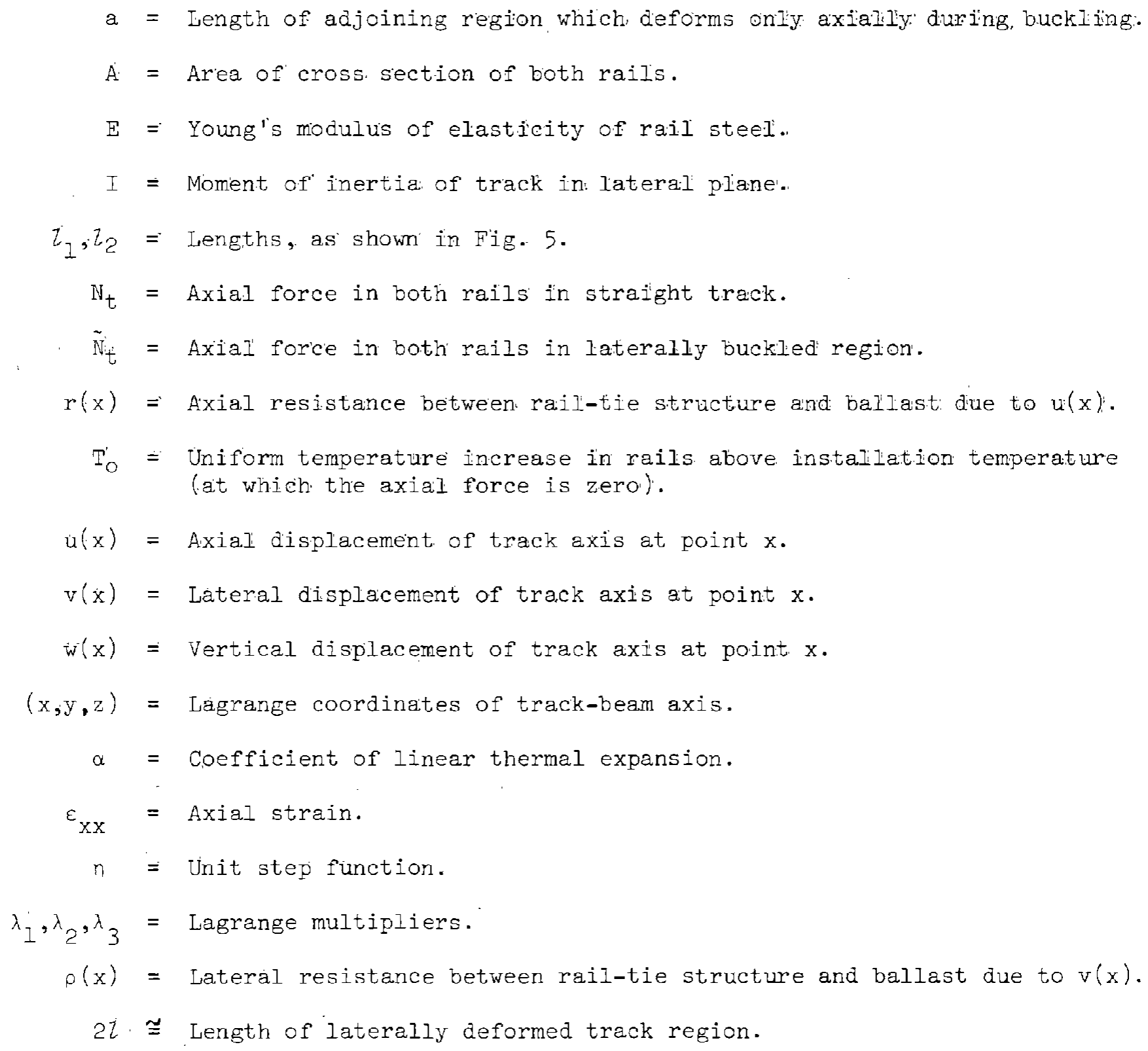




\section{INTRODUCTION}

Analyses for the determination of railroad track buckling, caused by a raise in temperature, were conducted in the past several decades by many investigators. These analyses may be grouped into two main categories: when track buckles vertically and when track buckles in the lateral plane. Although actual track buckling may proceed in a more complicated manner, the choice of these two special modes of deformation was apparently made in order to simplify the resulting analyses. These specialized analyses were also suggested by observations made on buckled tracks. Namely, according to field and test observations, cross-tie tracks when subjected to an excessive temperature increase, usually buckle in the lateral plane, as shown in Fig. 1. On the other hand when lateral motion is prevented, by an increased lateral rigidity and/or an increased lateral resistance, the track will buckle out in the vertical plane.

A critical survey of the analyses of thermal track buckling in the Lateral plane, and a description and discussion of related test results, were recently presented by A. D. Kerr [1]: This survey revealed that the majority of the published results are not suitable for analyzing thermal track buckling problems, because they are based on formulations which do not describe correctly the physical phenomenon under consideration. Those few analyses which are conceptually on the right path, exhibit analytical shortcomings with an unknown effect on the final results.

The purpose of the present paper is to present a mechanically reasonable and mathematically consistent analysis for the title problem. The obtained results are then compared with the relevant results published by other investigators.

\footnotetext{
*Numbers in brackets are reference numbers.
} 

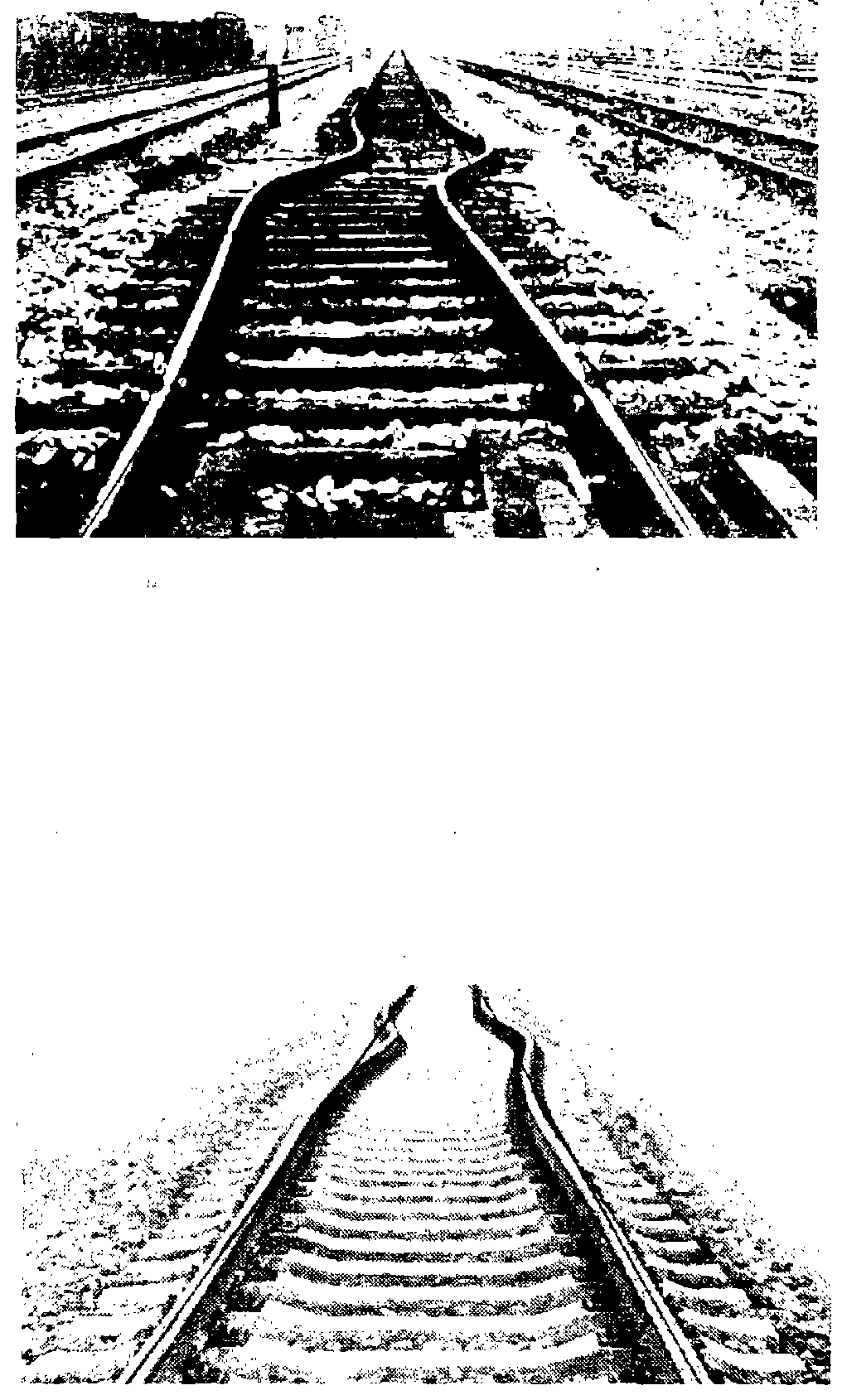

FIG. 1. BUCKLED TRACKS 
A uniform temperature increase, $T_{0}$, in a straight welded track induces in the two rails, due to constrained thermal expansions, an axial compression force (Fig. 2a)

$$
\mathrm{N}_{\mathrm{t}}=\mathrm{EAaT}_{0}
$$

In the above equation, which is valid when the rails respond elastically, $E$ is Young's modulus, $A$ is the cross-sectional area of the two rails, and $\alpha$ is the coefficient of linear thermal expansion. Thus, for a track with $115 \mathrm{lb} /$ yard rails $\left(E=2.1 \times 10^{6} \mathrm{~kg} / \mathrm{cm}^{2}, A=145 \mathrm{~cm}^{2}, \alpha=1.05 \times 10^{-5} 1 / \mathrm{C}^{0}\right)$, a uniform temperature increase of $30^{\circ} \mathrm{C}\left(54^{\circ} \mathrm{F}\right)$ induces in the rails an axial. compression force of 96 tons (metric).

For sufficiently large compression forces the tracks may buckle out. According to observations in the field and in track buckling tests [1], the continuously welded tracks presently in use buckle in the horizontal plane, as shown in Fig. 1. The observed buckling mode of a long straight track consists of a buckled region (of length 22 in Fig. 2) which exhibits large lateral deformations and the adjoining regions which appear to deform only axially.

In the buckiled region, a part of the constrained thermal expansions is released. This results in a reduction of the axial force to $\tilde{\mathbb{N}}_{t}$, which in the literature is assumed to be constant. In the adjoining regions, because of ballast resistance to axial displacements of the tracks, the constrained thermal expansions vary; so does the axial force $\tilde{\mathbb{N}}_{t} \leq \mathbb{N} \leq \mathbb{N}_{t}$, as shown schematically in Fig. 2(b). According to the above observations, thermal buckling of a long straight track appears to be a local phenomenon. 

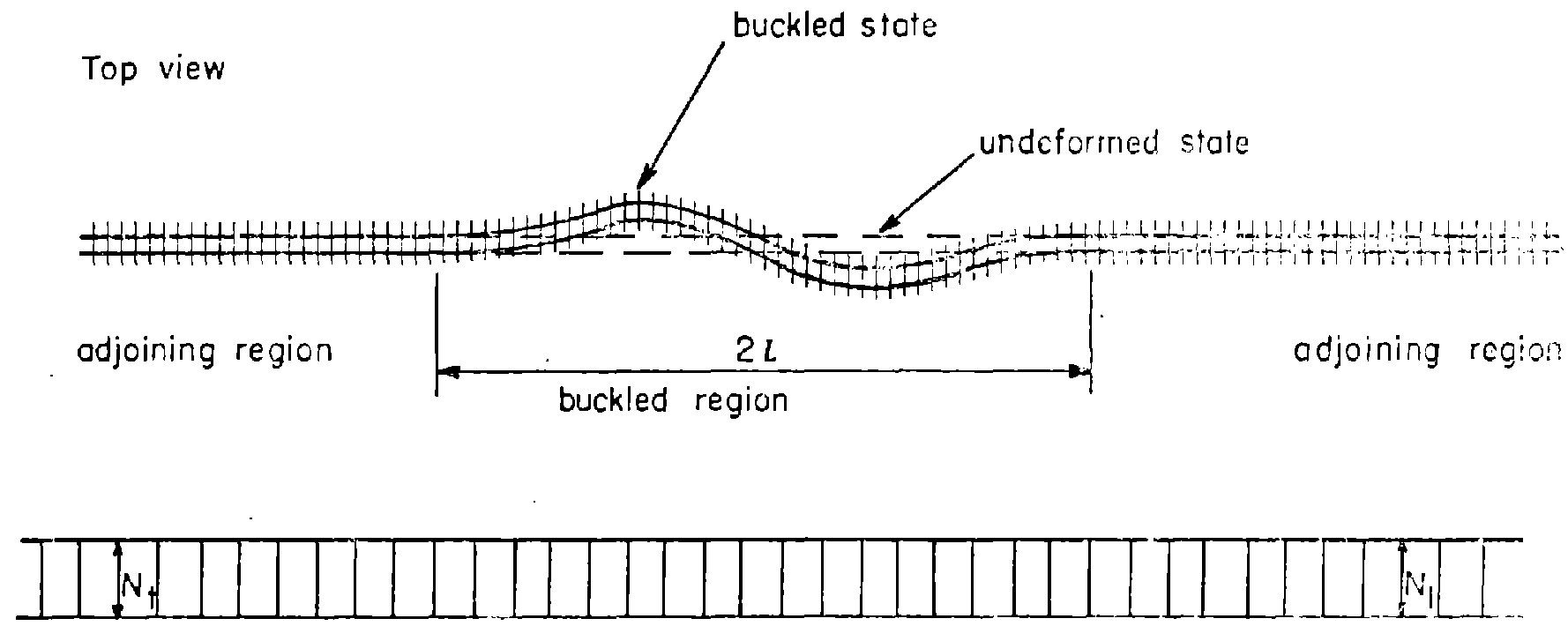

(a) Axial compression force before buckling

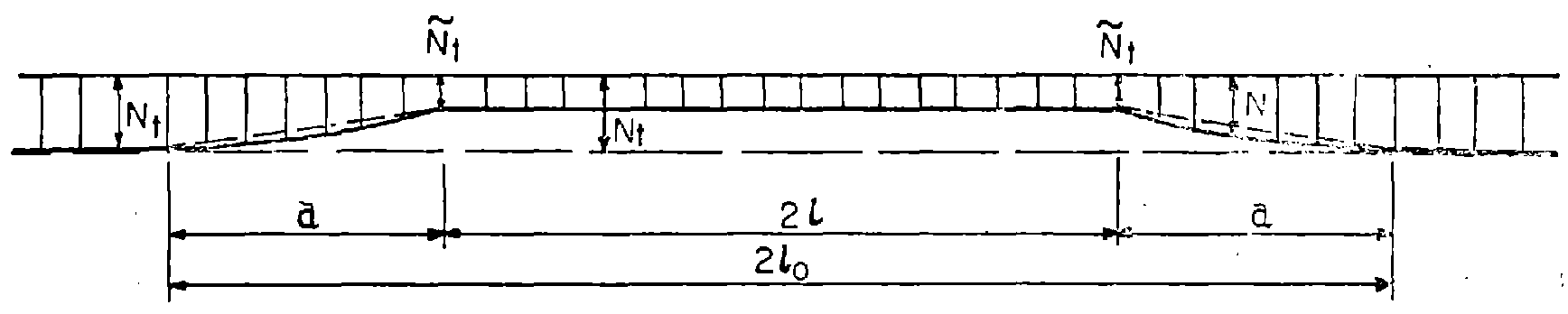

(b)Axial compression force after buckling

FIG. 2. DISTRIBUTION OF AXIAL COMPRESSION FORCES BEFORE AND AFTER BUCKLTNG (Note that in an actual track a is several times larger than $Z$ ) 


\section{ANALYTICAL PRELIMINARIES}

In the following analysis, the rail-tie structure is replaced by an equivalent beam of uniform cross-section, to be referred to as the track-beam, which is symmetrical with respect to the vertical $x-z$ plane. The $\mathrm{x}$-axis is placed through the centroid of the cross-section and is chosen as the reference axis.

It is assumed that the beam is subjected to a uniform temperature change*

$$
\mathrm{T}(\mathrm{x}, \mathrm{y}, \mathrm{z})=\mathrm{T}_{\mathrm{o}}=\text { const }
$$

and a uniformly distributed weight $q$ per unit length of track axis. This weight consists of the unit weight of two rails and the averaged weight of the cross-ties and fasteners per unit length of track.

To simplify the analysis, it is assumed that the vertical deflections of the rail-tie structure, prior and during buckling, are negligible. Thus, denoting by $w(x)$ the deflections in the vertical plane, it follows that

$$
w(x) \equiv 0
$$

This assumption was made by all investigators of lateral track buckIing reviewed in [1].

The lateral resistunce exerted by the ballast on the rail-tie structure (due to lateral displacements) consists of the friction forces between the bottom surface and the two long sides of the ties and the ballast, as woll as the pressure the ballast exerts against like front surface of the ties, as shown in Fig. 3(a). For the follow-

In a track, this change is measured from the installation temperature, (in the literature often called the "neutr.al" temperature) at which the axial forces in the rails are zero. 

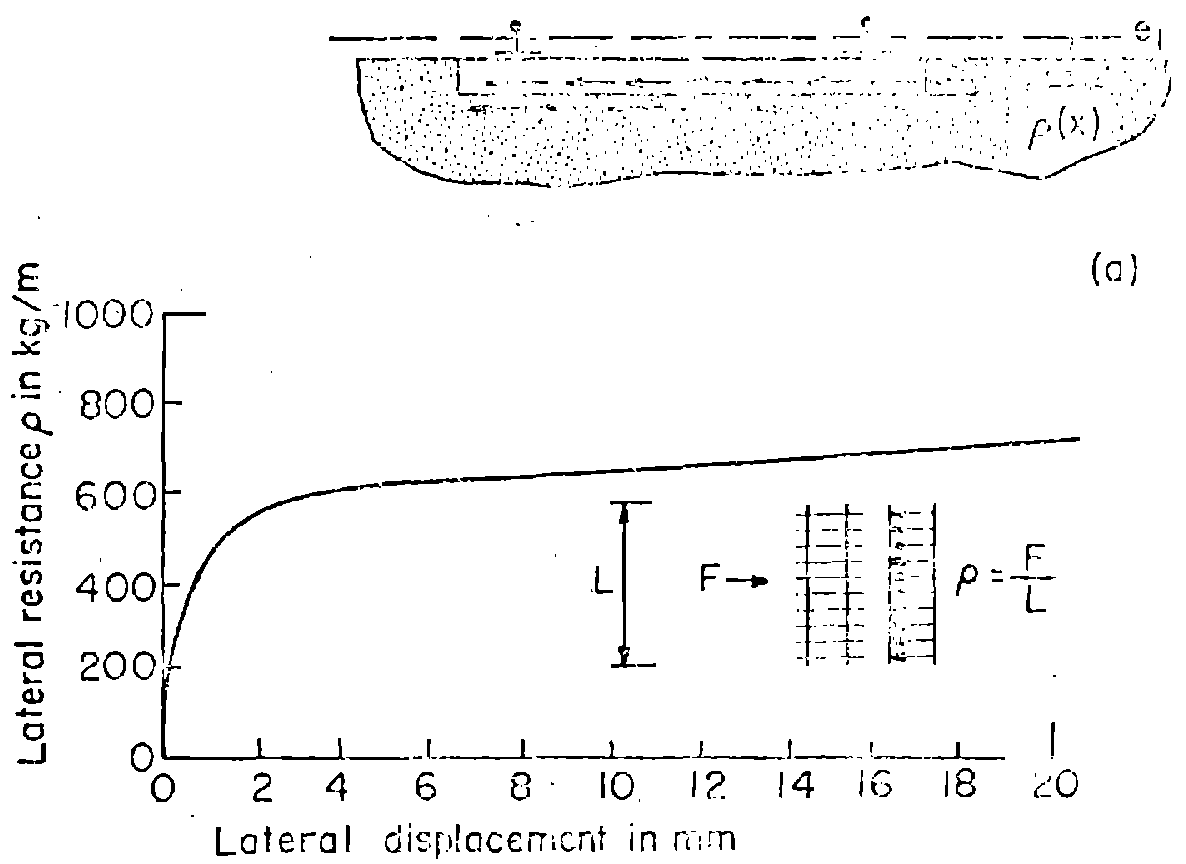

(a)

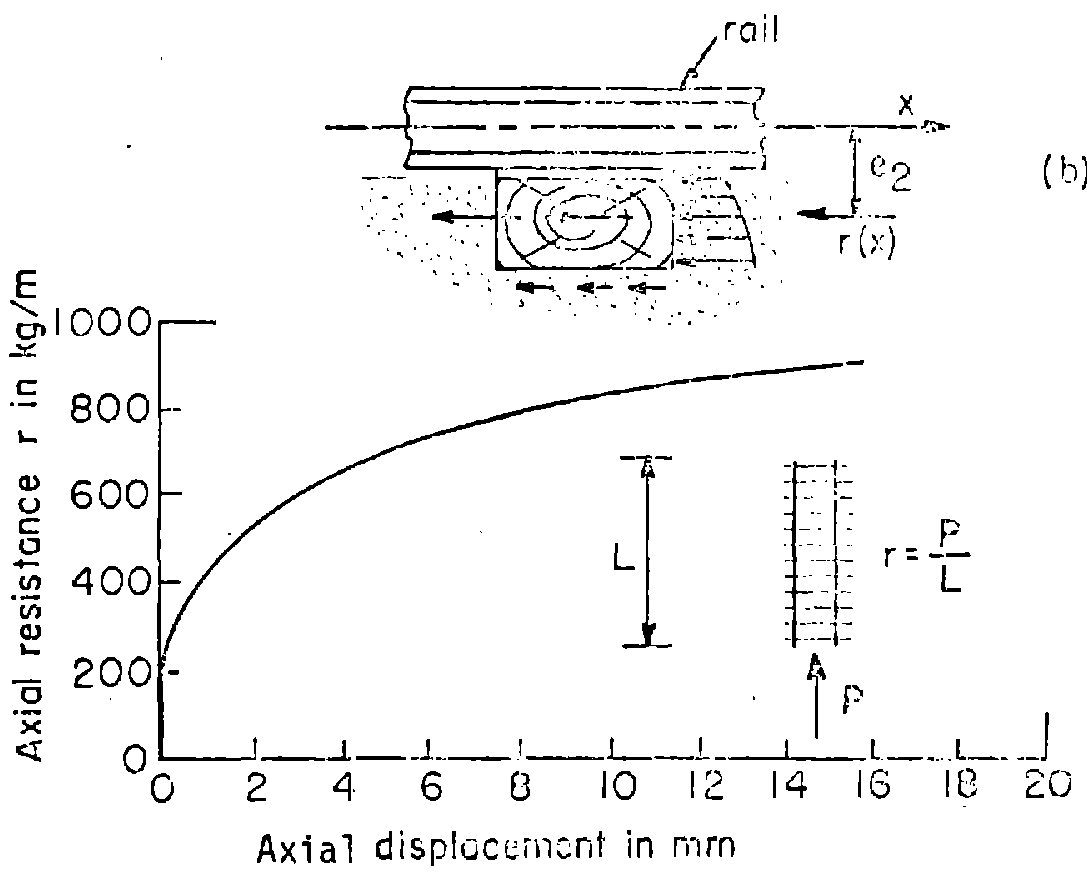

FIG. 3. LATERAL AND AXIAL TRACK RESISTANCE (Test results according to [2]) 
ing analysis it is assumed that the resulting lateral resistance is $\rho(x)$ (per unit length of track axis). This resistance acts at a distance $e_{I}$ below the reference axis. However, because of the assumption that prior and during buckling the track deforms only in its plane, thus $\mathrm{w}(\mathrm{x}) \equiv 0$, the eccentricity $e_{1}$ has no effect on the determined postbuckling response.

Tests, in which track sections were displaced laterally, revealed that the corresponding resistance vs. displacement graph is non-linear [2], as indicated in Fig. 3(a). However, as shown recently by A. D. Kerr [3], the simplifying assumption

$$
\rho(x)=\rho_{0}=\text { const. }
$$

may be sufficient for the determination of the safe temperature increase. This finding will be utilized in the following analysis.

The axial resistance exerted by the ballast on the rail-tie structure (due to axial displacements) consists of the resistance between the ballast and the bottom surface of the ties and the pressure on the vertical tie surface exerted by the ballast in the cribs, as shown in Fig. 3(b). In the following analysis it is assumed that the resulting axial resistance is $r(x)$ (per unit length of track axis) and that it acts at a distance $e_{2}$ below the reference axis. Because of the assumption that $w(x) \equiv 0$, also for this case the $e_{2}$-value has no effect on the determined post-buckling response. In this connection note the corresponding derivations presented in Ref. [4].

Tests, in which track sections were displaced axially, revealed that the corresponding resistance vs. displacenent graph is non-linear [2], as shown in Fig.3 (b). Following the practice of a number of 
track buckling investigators (whose results will be compared in Section $V$ with those obtained in the present paper), in the following analysis it is assumed that the resistance in the adjoining regions is

$$
r(x)=r_{0}=\text { const }
$$

and that it is negigibly small in the buckled zone. This second assumption, which simplifies the solution, was made in all track buckling analyses reviewed in [1]. It may be partly justified by the observation made in the field that lateral buckling is often initiated by a slight lift-off of the rail-tie structure for example in front or rear of a whel set) which eliminates the friction force between the ballast and the bottom surface of the ties.

Furthermore, it is assumed that prior and during buckling the response of the rail-tie structure is elastic.

The buckling analysis of a railroad track subjected to thermal compression forces consists of two parts: (1) the determination of all equilibrium. states and (2) the inspection, which of the determined equilibrium states are stable and which are not. From the nature of the post-buckling equilibrium branches and their stability, established in Refs. [5] it follows that the range of "safe" temperature increases to prevent track buckling may be determined solely from the post-buckling equilibrizm branches. This concept is adopted in the following analysis.

To insure a formulation that is consistent, mechanically and mathematically, the equilibrium equations for the track-beam are derived 
by utilizing the nonlinear theory of elasticity and the principle of virtual displacements. To avoid the difficulties encountered by other investigators (to be discussed in section $V$ ) when matching track regions which are governed by different differential equations and whose matching points are not fixed a priori along the track axis, use is made of variational calculus for variable matching points [6].

With the notation of Ref. [7] Chapter III, the principle of virtual displacements may be stated as

$$
\delta U-\iiint_{V} \overrightarrow{\mathrm{F}}^{*} \cdot \delta \bar{u} \mathrm{dV}-\iint_{S_{1}} \mathrm{f}^{*} \cdot \delta \bar{u} \mathrm{dS}=0
$$

where

$$
U=\frac{1}{2} \iiint\left(\sigma_{\mathrm{xx}}^{*} \varepsilon_{\mathrm{xx}}+\sigma_{\mathrm{yy}}^{*} \mathrm{y}_{\mathrm{yy}}+\sigma_{\mathrm{zz}}^{*} \mathrm{z}_{\mathrm{z} z}+\sigma_{\mathrm{xy}}^{*}{ }_{\mathrm{xy}}+\sigma_{\mathrm{xz}}^{*} \mathrm{xz}^{+}+\sigma_{\mathrm{yz}}^{*} \varepsilon_{\mathrm{yz}}\right) \mathrm{dV}
$$

is the elastic strain energy of the track-beam, $V$ is its volume in the undeformed state, $\bar{u}$ is the displacement vector, $\sigma_{i j}^{*}$ are generalized stresses, $E_{i j}$ are Langrangian strains, $\bar{F}^{*}$ is the body force of the track-bean, and $f^{*}$ is the traction force which acts on part $S_{1}$ of the track-beam surface $\mathrm{S}$.

The coordinate system used and the position of the track-beam, before and after deformation, are shown in Fig. 4 . Note that $(x, y, z)$ are Lagrange coordinates, $(u, v, w)$ are the components of the displacement vector $\bar{u}$ of point $(x, y, z)$, and $(\hat{)})$ are variables which refer to the reference axis $x$. 
With the usual assumptions of the bending theory of beams (such as the plane section hypothesis*, etc.) the expression for $U$ reduces to

$$
U=\int_{x_{1}}^{x_{2}} \frac{1}{2}\left[E A\left(\hat{\varepsilon}_{x x}-\alpha T_{0} j^{2}+E I \hat{v}^{\prime \prime}\right] d x\right.
$$

where $A$ is the cross-sectional area of the track-beam, I is its moment of inertia with respect to the vertical z-axis, aT is the thermal strain,

$$
\hat{\varepsilon}_{x x}=\hat{u}^{\prime}+\frac{1}{2} \hat{v}^{\prime 2}
$$

and ()$^{\prime}=d() / d x$. The derivation of the above relations (which also includes the order of magnitude estimates of the retained and neglected nonlinear terms) is identical to the one presented in Ref. [4], except that $\mathrm{w}$ and $\mathrm{v}$ are to be interchanged.

* It should be noted that the plane section hypothesis, although utilized by track investigators, is not satisfied for the lateral deformation of many tracks. However, because the cut-spike rail-tie fastener, currently used by U.S. railroads, exhibits only a very small rotational resistance, it appears justified to assume that for such tracks this hypothesis is valid for each rail and that the lateral bending rigidity of the track is the sum of the bending rigidities of the two rails with respect to their vertical axes; thus $I=2 I_{r}$. A thorough re-examination of the effect of the fastener rigidity on the lateral track response, will be contained in a fortheoming report. 


\section{ANALYSES OF TRACK BUCKLING}

Because of assumption (3.4), which states that the axial track resistance is constant, it follows that in the adjoining track regions the axial track force varies linearly, as indicated by the dashed line in Fig. 2(b). Therefore the length of these regions, which exhibit only axial displacemnts, is finite; namely $a=\left|N_{t}-\dot{N}_{t}\right| / r_{0}$. According to this scheme, beyond $2(z+a)$ the track does not deform due to buckling, which agrees with observations in the field.

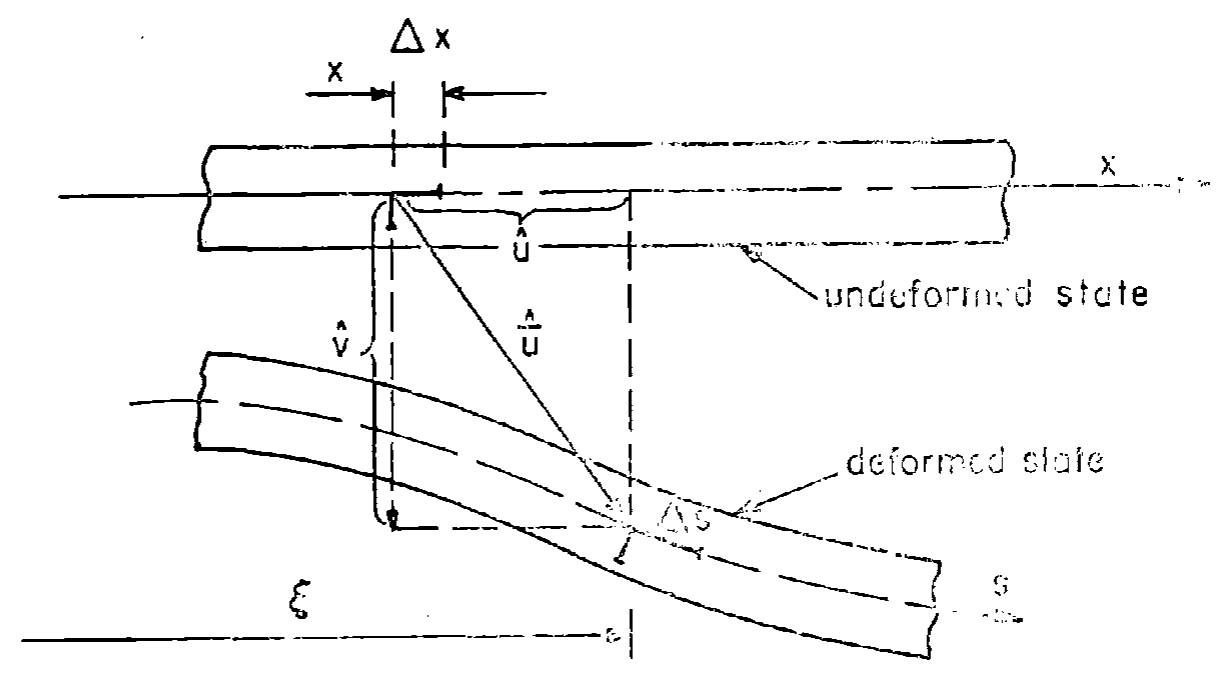

FIG. 4. NOTATION AND CONVENTION USED IN ANALYSIS 
As shown in Fig. 1, the lateral buckling modes of a track tend to be symmetrical or antisymmetrical. Since the lateral resistance $\rho_{0}$ is always opposite to the airection of $v(x)$, it follows that the simplest analysis for each of these modes is obtained when the lateral displacements are assumed to be of form I or II, respectively, as shown in Fig. 5 .

In an actual track, the lateral displacements are not zero beyond $l=l_{1}$. To study the effect this constraint has on the analytical results, it will be relaxed by allowing the formation of additional half waves beyond $Z_{I}=Z$. This results in shapes III and IV shown in Fig. 5. The necessary analyses are more complicated, since more domains governed by different differential equations have to be matched.

In the following, the post-buckling equilibrium states of the trackbeam are determined for the deformation patterns I to IV, shown in Fig. 5 . The obtained results are compared first with each other, in order to determine the effect of the constraints on the lateral displacements made in shapes I and II. They are then compared with the corresponding results of A. Martinet [8], K. N. Mishchenko [9], and M. Numata [10].

\subsection{ANALYSIS FOR SYMMETRICAL DEFORMATION SHAPE I}

\section{I.1 Formulation of Problem}

For this analysis the track consists of five regions: the laterally buckled zone of length 22 , two adjoining regions each of length a

for which $\hat{\mathrm{v}}(\mathrm{x}) \equiv 0$, and the two infinite regions in $|\mathrm{x}| \geqq 2_{0}$ which are not affected by bucking, but which are subjected to the axial compression force $\mathrm{N}_{t}=\mathrm{EA \alpha T}_{0}$. 
Shope 1

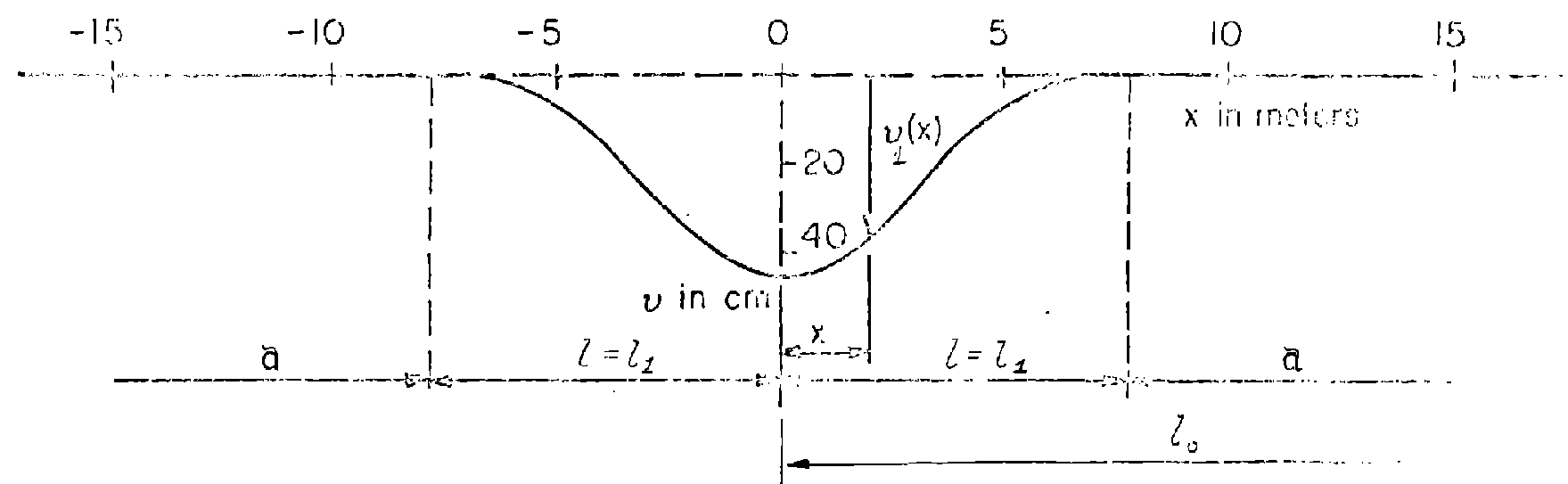

Shope:11
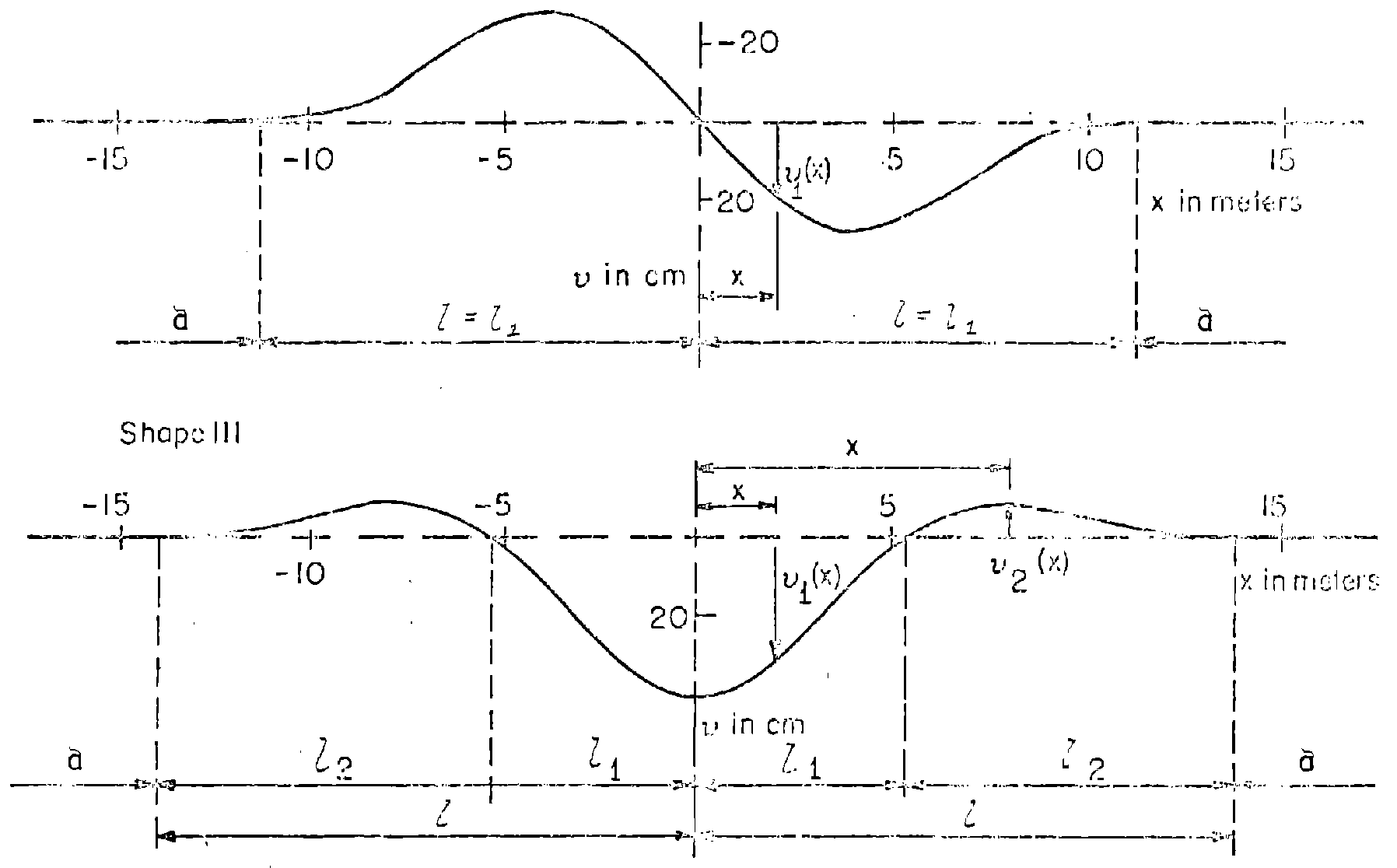

Shape IV

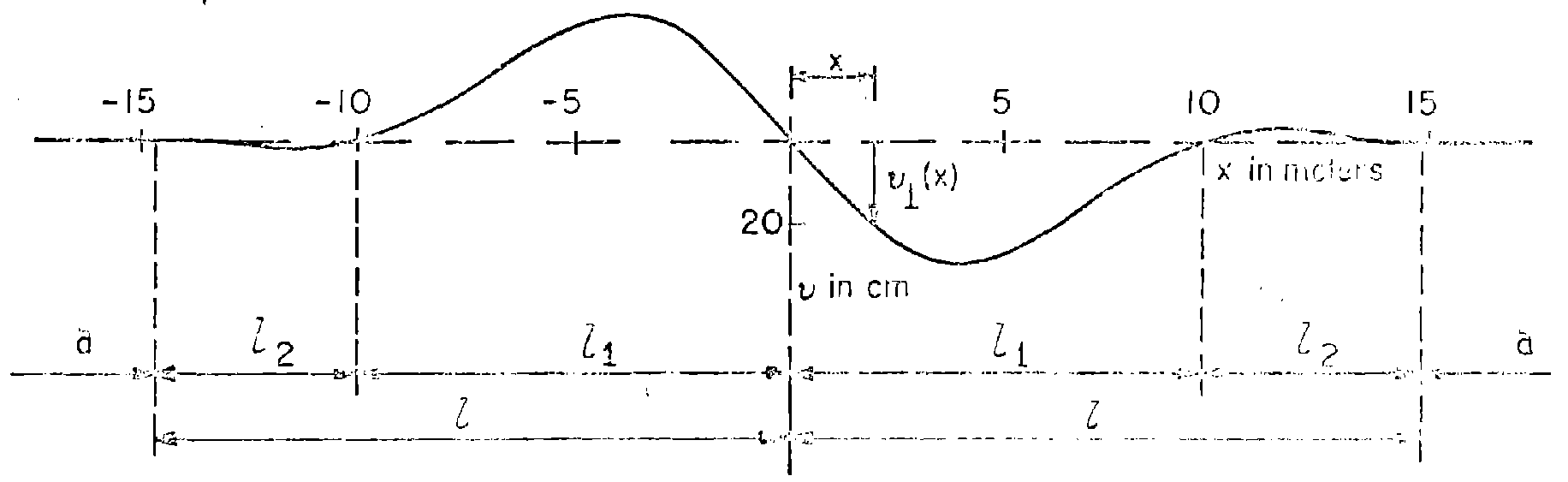

FIG. 5. LATERAL DEFLECTION SHAPES 
Because of the assumed symmetry of the buckled zone, eq. (3.5)

may be written as follows:

$$
\delta\left\{\int_{0}^{l} F_{1} d x+\int_{l}^{Z_{0}} F_{a} d x+\int_{Z_{0}}^{\infty} F_{\infty} d x+\lambda_{2} \hat{v}_{a}(z)+\lambda_{3} \hat{v}_{a}^{\prime}(z)\right\}=0
$$

where

$$
\left.\begin{array}{l}
F_{I}=\frac{1}{2}\left[E A\left(\hat{\varepsilon}_{I}-\alpha T_{0}\right)^{2}+E I \hat{v}_{1}^{\prime \prime 2}\right]-\eta(x-l) r_{0} u_{I}+\rho_{0} \hat{v}_{I} \\
\left.F_{a}=\frac{1}{2}\left[E A\left(\hat{\varepsilon}_{a}-\alpha T_{0}\right)^{2}+E I \hat{v}_{a}^{\prime \prime 2}\right]-\eta(x-l) r_{0} u_{a}+\rho_{0} \hat{v}_{a}-\lambda_{I} \hat{v}_{a}\right)(4.2)^{*} \\
F_{\infty}=\frac{1}{2}\left[E A\left(\hat{\varepsilon}_{\infty}-\alpha I_{0}\right)^{2}+E I v_{\infty}^{\prime \prime 2}\right]-\eta(x-l) r_{0} \hat{u}_{\infty}+\rho_{0} \hat{v}_{\infty}
\end{array}\right\}
$$

and

$$
\hat{\varepsilon}_{n}=\hat{u}_{n}^{\prime}+\frac{1}{2} \hat{v}_{n}^{\prime 2} \quad n=1, a, \infty
$$

subject to the constraint conditions in $l \leqq x \leqq Z_{0}$

$$
\begin{aligned}
& \hat{v}_{a}(x) \equiv 0 \rightarrow \hat{v}_{a}(x)=\hat{v}_{a}^{\prime}(x)=\ldots .=0 \\
& \hat{u}_{a}\left(z_{0}\right)=0
\end{aligned}
$$

and in $Z_{0} \leq x<\infty$

$$
\begin{aligned}
& \hat{\mathrm{v}}_{\infty}(\mathrm{x}) \equiv 0 \\
& \hat{\mathrm{u}}_{\infty}(\mathrm{x}) \equiv 0 \quad \text { (Note that } \mathbb{N}_{t}=\mathrm{EA \alpha T}_{0} \neq 0 \text { ) }
\end{aligned}
$$

The subscript 1 refers to the buckled region, the subscript a to the adjoining regions, and the subscript $\infty$ to the $x \geq l_{0}$ region. $n(x-l)$ is the unit step function attached to the axial resistance $r_{0}$. Note that $r_{0} \neq 0$ only when $u \neq 0$ and that $\rho_{0} \neq 0$ only when $v \neq 0$.

The variational equation (4.1) contains three Lagrange multipliers. They enter because of the assumed constraint $\hat{v}_{a}(x) \equiv 0$ for $l \leqq x \leq l_{0}$.

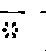

Since $r_{0}$ and $p_{0}$ are assumed not to be functions of the respective displacements, their direction has to be prescribed as opposite to the corresponding onticipated displacements. 
The mulijplier $\lambda_{1}$ is the lateral reaction pressure which mar occur in $Z \leqq x \leqq Z_{0}$. The multiplier $\lambda_{2}$ is the anticipated concentrated lateral reaction force at the points $\mathrm{x}=\imath$, which usually occurs because of the use of the beam bending theory and the stipulation $\hat{v}_{a}(x) \equiv 0$. The multiplier $\lambda_{3}$ is a concentrated reaction moment which may occur at $x=2$. (If it does not occur, the analysis will yield $\lambda_{3}=0$. ) Since $x=2$ and $x=l_{0}$ are variable matching points, eq. (4.1) becomes, according to [6],

$$
\begin{aligned}
\delta \int_{0}^{l} F_{l} d x & +\delta \int_{l}^{Z_{0}} F_{a} d x+\int_{l_{0}}^{\infty} F_{\infty} d x+\left[F_{l}-F_{a}\right]_{l} \delta l \\
+ & {\left[F_{a}-F_{\infty}\right]_{z_{0}} \delta z_{0}+\lambda_{2} \delta \hat{v}_{a}(l)+\lambda_{3} \delta \hat{v}_{a}^{\prime}(z)=0 }
\end{aligned}
$$

Performing the variations, then integrating by parts, and grouping terms containing the same variation, eq. (4.4) becomes**

$$
\begin{aligned}
& \int_{0}^{l}\left[\left\{\left(E I v_{1}^{\prime \prime}\right)^{\prime \prime}-\left[E A\left(\varepsilon_{1}-\alpha T_{0}\right) v_{1}^{\prime}\right]^{\prime}+\rho_{0}\right\} \delta v_{1}-\left\{\left[E A\left(\varepsilon_{1}-\alpha T_{0}\right)\right]^{\prime}+\eta(x-l) r_{0}\right\} \delta u_{1}\right] d x \\
& +\int_{\tau}^{\tau}\left[\left\{\left(E I v_{a}^{\prime \prime}\right)^{\prime \prime}-\left[E A\left(\varepsilon_{a}-\alpha T_{0}\right) v_{a}^{\prime}\right]^{\prime}+p_{0}-\lambda I\right\} \delta v_{a}-\left\{\left[E A\left(\varepsilon_{a}-\alpha T_{0}\right)\right]^{\prime}+\eta(x-Z) r_{0}\right\} \delta u_{a}\right] d x
\end{aligned}
$$

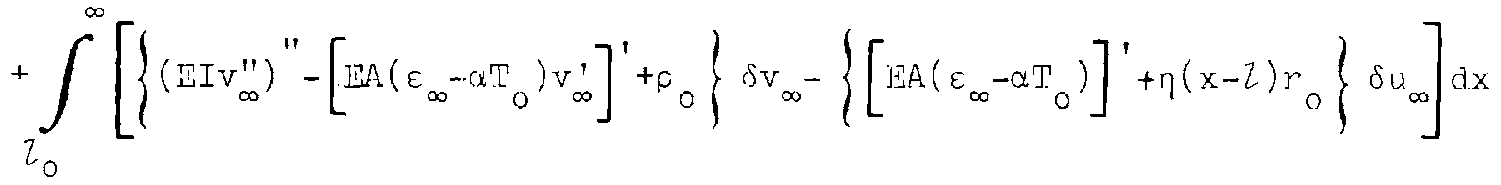

$$
\begin{aligned}
& +\left\{-\left[-\left(E I v_{1}^{\prime \prime}\right)^{\prime}+E A\left(\varepsilon_{1}-\alpha T_{0}\right) v_{1}^{\prime}\right] \delta v_{I}-\left[E I v_{I}^{\prime \prime}\right] \delta v_{1}^{\prime}-\left[E A\left(\varepsilon_{1}-\alpha T_{0}\right)\right] \delta u_{1}\right\}_{x=0}+
\end{aligned}
$$

* Note that the corresponding conentrated axial resistance was not included because the necessary "friction" coefficient is not known and because its effect is not expected to be essential. In this connection note the related results for shape III.

* Since in (4.4) all variables refer to the reference axis, in the following the ( $($ ) symbol is dropped to simplify the presentation. 


$$
\begin{aligned}
& +\left\{\left[-\left(E I v_{1}^{\prime \prime}\right)^{\prime}+E A\left(\varepsilon_{1}-\alpha T_{0}\right) v_{I}^{\prime}\right] \delta v_{I}-\left[-\left(E I v_{a}^{\prime \prime}\right)^{\prime}+E A\left(\varepsilon_{a}-\alpha T_{0}\right) v_{a}^{\prime}-\lambda_{2}\right] \delta v_{a}\right. \\
& \left.+\left[E I v_{I}^{\prime \prime}\right] \delta v_{1}^{\prime}-\left[E I v_{a}^{\prime \prime}-\lambda_{3}\right] \delta v_{a}^{\prime}+\left[E A\left(\varepsilon_{1}-\alpha T_{0}\right)\right] \delta u_{I}-\left[E A\left(\varepsilon_{a}-\alpha T_{0}\right)\right] \delta u_{a}+\left[F_{I}-F_{a}\right] \delta z\right\} \\
& +\left\{\left[-\left(E I v_{a}^{\prime \prime}\right)^{\prime}+E A\left(\varepsilon_{a}-\alpha T_{0}\right) v_{a}^{\prime}\right] \delta v_{a}-\left[-\left(E I v_{\infty}^{\prime \prime}\right)^{\prime}+E A\left(\varepsilon_{\infty}-\alpha T_{0}\right) v_{\infty}^{\prime}\right] \delta v_{\infty}\right. \\
& \left.+\left[E I v_{a}^{\prime \prime}\right] \delta v_{a}^{\prime}-\left[E I v_{\infty}^{\prime \prime}\right] \delta v_{\infty}^{\prime}+\left[E A\left(\varepsilon_{a}-\alpha T_{0}\right)\right] \delta u_{a}-\left[E A\left(\varepsilon_{\infty}-\alpha T_{0}\right)\right] \delta u_{\infty}+\left[F F_{a}-F\right]_{\infty}\right\}_{x=z_{0}} \\
& +\left\{\left[-\left(E I v_{\infty}^{\prime \prime}\right)^{\prime}+E A\left(\varepsilon_{\infty}-\alpha T_{0}\right) v_{\infty}^{\prime}\right] \delta v_{\infty}+\left[E I v_{\infty}^{\prime \prime}\right] \delta v_{\infty}^{\prime}+\left[E A\left(\varepsilon_{\infty}-\alpha T_{0}\right)\right] \delta u_{\infty}\right\}_{x=\infty}=0
\end{aligned}
$$

From the above equation it follows that the differential equations for the track are:

In the buckled region, $0 \leq x \leq l$, noting that in this domain $\eta(x-\tau)=0$,

$$
\begin{gathered}
\left(\operatorname{EIV} v_{1}^{\prime \prime}\right)^{\prime \prime}-\left[E A\left(\varepsilon_{1}-\alpha T_{0}\right) v_{1}^{\prime}\right]^{\prime}=-p_{0} \\
{\left[F A\left(\varepsilon_{1}-\alpha T_{0}\right)\right]^{\prime}=0}
\end{gathered} \mid
$$

and in the adjoining region, $Z \leqq x \leqq Z_{0}$, noting that in this domain $\eta(x-l)=1, v_{a}(x) \equiv 0$ and hence also $\rho_{0}=0$,

$$
\left.\begin{array}{r}
\lambda_{1}=0 \\
{\left[E A\left(\varepsilon_{a}-\alpha T_{0}\right)\right]^{\prime}=-r_{0}}
\end{array}\right\}
$$

where

$$
E_{n}=u_{n}^{\prime}+\frac{1}{2} v_{n}^{\prime 2} \quad n=1, a
$$

In region $z_{0} \leq x \leq \infty$, as stated in $(4.3), u_{\infty}(x) \equiv 0, v_{\infty}(x) \equiv 0$, and $N_{t}=1: 1 n n_{0}^{\prime \prime}$.

From eq. (4.5) it also follows that the boundary conditions at $\mathrm{x}=0$ are 


$$
\begin{aligned}
u_{1}(0) & =0 \\
v_{1}^{\prime}(0) & =0 \\
{\left[-\left(\text { EIv }_{1}^{\prime \prime}\right)^{\prime}\right]_{0} } & =0
\end{aligned}
$$

Because of the constraint conditions $v_{\infty}(x) \equiv 0$ and $u_{\infty}(x) \equiv 0$, the boundary term at $x=\infty$ in eq. (4.5) vanishes.

The matching conditions at $x=Z$ and $x=Z_{0}$ are obtained from the remaining terms in (4.5); namely the boundary brackets at $x=2$ and $x=\tau_{0}$. Because of the geometric continuity conditions

$$
\begin{aligned}
& v_{I}(z)=v_{a}(z) \\
& v_{I}^{\prime}(z)=v_{a}^{\prime}(z) \\
& u_{1}(z)=u_{a}(z)
\end{aligned}
$$

it follows that at $x=2$

$$
\delta v_{I}(z)=\delta v_{a}(z) ; \quad \delta v_{1}^{\prime}(z)=\delta v_{a}^{\prime}(z) ; \delta u_{1}(z)=\delta u_{a}(z)
$$

Similarly, at $x=l_{0}$,

$$
\delta v_{a}\left(z_{0}\right)=\delta v_{\infty}\left(z_{0}\right) ; \quad \delta v_{a}^{\prime}\left(z_{0}\right)=\delta v_{\infty}^{\prime}\left(z_{0}\right) ; \quad \delta u_{a}\left(z_{0}\right)=\delta u_{\infty}\left(z_{0}\right)
$$

Thus, the remaining terms in (4.5) may be written as

$$
\begin{aligned}
& \left\{\left[-\left(E I v_{l}^{\prime \prime}\right)^{\prime}+E A\left(\varepsilon_{1}-\alpha T_{0}\right) v_{l}^{\prime}+\left(E I v_{a}^{\prime \prime}\right)^{\prime}-E A\left(\varepsilon_{a}-\alpha T_{0}\right) v_{a}^{\prime}+\lambda{ }_{2}\right] \delta v_{1}\right. \\
& \left.+\left[E I v_{1}^{\prime \prime}-E I v_{a}^{\prime \prime}+\lambda_{3}\right] \delta v_{1}^{\prime}+\left[E A\left(\varepsilon_{1}-\alpha T_{0}\right)-E A\left(\varepsilon_{a}-\alpha T_{0}\right)\right] \delta u_{1}+\left[F_{1}-F_{a}\right] \delta z\right\}_{x=l} \\
& +\left\{\left[-\left(E I v_{a}^{\prime \prime}\right)^{\prime}+E A\left(\varepsilon_{a}-\alpha T_{0}\right) v_{a}^{\prime}+\left(E I v_{\infty}^{\prime \prime}\right)^{\prime}-E A\left(\varepsilon_{\infty}-\alpha T_{0}\right) v_{\infty}^{\prime}\right] \delta v_{a}\right. \\
& \left.+\left[E I v_{a}^{\prime \prime}-E I v_{\infty}^{\prime \prime}\right] \delta v_{a}^{\prime}+\left[E A\left(\varepsilon_{a}-\alpha T_{0}\right)-E A\left(\varepsilon_{\infty}-\alpha T_{0}\right)\right] \delta u_{a}+\left[F_{a}-F F_{\infty}\right] \delta z_{0}\right\}_{x=z_{0}}=0
\end{aligned}
$$


However, in the above equation $\delta v_{1}(l), \delta v_{l}^{\prime}(l)$, etc. are not the variations of the variable end point 2 , as shown for $v_{1}$ in Fig. 6 . According to Fig. 6, for the general case (needed because the constraint conditions were taken into consideration by means of Lagrange multipliers)

$$
\delta v_{1}(z)=\delta v_{1 z}-v_{1}^{\prime}(z) \delta z \quad ; \quad \delta v_{a}\left(z_{0}\right)=\delta v_{a 0}-v_{a}^{\prime}\left(z_{0}\right) \delta z_{0}
$$

and similarly

$$
\begin{aligned}
& \delta v_{i}^{\prime}(Z)=\delta v_{i Z}^{\prime}-v_{l}^{\prime \prime}(Z) \delta z \quad ; \quad \delta v_{a}^{\prime}\left(Z_{0}\right)=\delta v_{a 0}^{\prime}-v_{a}^{\prime \prime}\left(z_{0}\right) \delta Z_{0} \\
& \delta u_{1}^{\prime}(z)=\delta u_{1 l}-u_{l}^{\prime}(z) \delta z \quad ; \quad \delta u_{a}\left(z_{0}\right)=\delta u_{a_{0}}-u_{a}^{\prime}\left(z_{0}\right) \delta z_{0}
\end{aligned}
$$

With these relationships, eq. (4.5') becomes

$$
\begin{aligned}
& {\left[-\left(E I v_{1}^{\prime \prime}\right)^{\prime}+E A\left(\varepsilon_{1}-\alpha T_{0}\right) v_{1}^{\prime}+\left(E I v_{a}^{\prime \prime}\right)^{\prime}-E A\left(\varepsilon_{a}-\alpha T_{0}\right) v_{a}^{\prime}+\lambda_{2}\right]_{l} \delta v_{1 l}} \\
& +\left[E_{1} v_{1}^{\prime \prime}-E I v_{a}^{\prime \prime}+\lambda_{3}\right]_{2} \delta v_{1}^{\prime} Z^{+}\left[E A\left(\varepsilon_{1}-\alpha T_{0}\right)-E A\left(\varepsilon_{a}-\alpha T_{0}\right)\right]_{2} \delta u_{1} \\
& -\left\{\left[-\left(E I v_{I}^{\prime \prime}\right)^{\prime}+E A\left(\varepsilon_{1}-\alpha T_{0}\right) v_{1}^{\prime}+\left(E I v_{a}^{\prime \prime}\right)^{\prime}-E A\left(\varepsilon_{a}-\alpha T_{0}\right) v_{a}^{\prime}+\lambda_{2}\right]_{1}^{\prime}\right. \\
& \left.+\left[E I v_{1}^{\prime \prime}-E I v_{a}^{\prime \prime}+\lambda_{3}\right] v_{1}^{\prime \prime}+\left[E A\left(\varepsilon_{1}-\alpha T_{0}\right)-E A\left(\varepsilon_{a}-\alpha T_{0}\right)\right] u_{l}^{\prime}-\left[F_{1}-F_{a}\right]\right\}_{l} \delta l \\
& +\left[-\left(E I v_{a}^{\prime \prime}\right)^{\prime}+E A\left(\varepsilon_{a}-\alpha T_{0}\right) v_{a}^{\prime}+\left(E I v_{\infty}^{\prime \prime}\right)^{\prime}-E A\left(\varepsilon_{\infty}-\alpha T_{0}\right) v_{\infty}^{\prime}\right]_{Z_{0}} \delta v_{a 0} \\
& +\left[E I v_{a}^{\prime \prime}-E I v_{\infty}^{\prime \prime}\right]_{\tau_{0}} \delta v_{a 0}^{\prime}+\left[E A\left(\varepsilon_{a}-\alpha T_{0}\right)-E A\left(\varepsilon_{\infty}-\alpha T_{0}\right)\right]_{\tau_{0}} \delta u_{a 0} \\
& -\left\{\left[-\left(E I v_{a}^{\prime \prime}\right)^{\prime}+E A\left(\varepsilon_{a}-\alpha T_{0}\right) v_{a}^{\prime}+\left(E I v_{\infty}^{\prime \prime}\right)^{\prime}-E A\left(\varepsilon_{\infty}-\alpha T_{0}\right) v_{\infty}^{\prime}\right]_{a}^{\prime}\right. \\
& \left.+\left[E I v_{a}^{\prime \prime}-E I v_{\infty}^{\prime \prime}\right] v_{a}^{\prime \prime}+\left[E A\left(\varepsilon_{a}-\alpha T_{0}\right)-E A\left(\varepsilon_{\infty}-\alpha T_{0}\right)\right] u_{a}^{\prime}-\left[F_{a}-F_{\infty}\right]\right\}_{l} \delta z_{0}=0
\end{aligned}
$$

In the above equation, all variations are independent. Thus, in addition to the geometrical matching conditions (4.9) subject to the constraint conditions in (4 3), which reduce to 


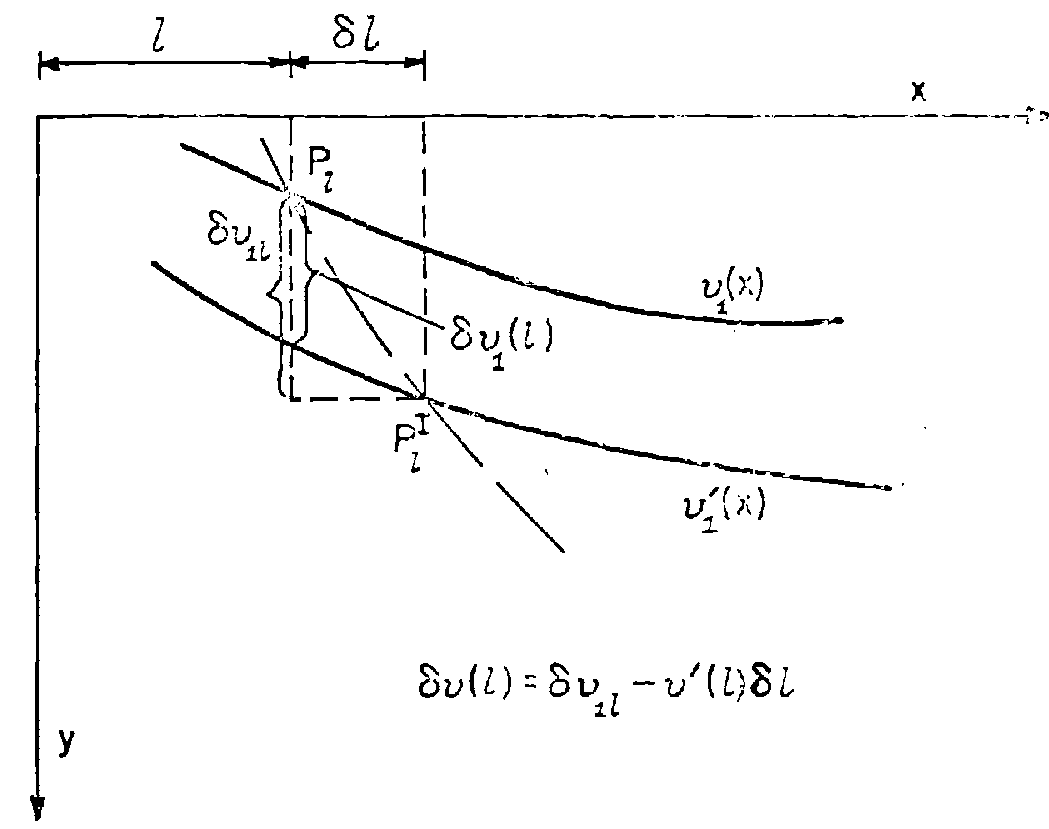

FIG. 6. RELATIONS AT THE VARIABLE MATCHING POINT $x=\imath$

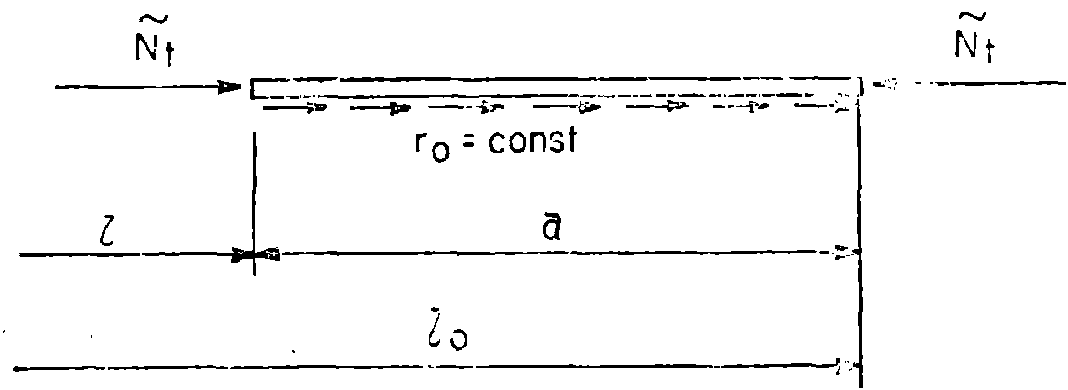

FIG. 7. MECHANICAL INTERPRETATION OF A DERIVED CONDITION 


$$
\begin{aligned}
& v_{I}(l)=0 \\
& v_{I}^{\prime}(z)=0 \\
& u_{I}(z)=u_{a}(z)
\end{aligned}
$$

also the following conditions have to be satisfied at $x=l$

$$
\left.\begin{array}{rl}
u_{1}^{\prime}(l) & =u_{a}^{\prime}(l) \\
\operatorname{EIv}_{1}^{\prime \prime}(l) & =-\lambda_{3} \\
-\left[\left(\operatorname{EIv}_{1}^{\prime \prime}\right)^{\prime}\right]_{l} & =-\lambda_{2} \\
v_{I}^{\prime \prime}(l) & =0 \quad \text { (transversality condition) }
\end{array}\right\}
$$

and at $x=z_{0}$, noting $\left(4.3^{\prime}\right)$,

$$
\left.\begin{array}{l}
u_{a}\left(z_{0}\right)=0 \\
u_{a}^{\prime}\left(z_{0}\right)=0 \quad \text { (transversality condition) }
\end{array}\right\}
$$

For a physical interpretation of the obtained boundary and matching conditions, it should be noted that the axial force, bending moment, and shearing force in the lateral plane of the track-beam are expressed respectively as:

$$
\left.\begin{array}{l}
\mathbb{N}_{n}(x)=-E A\left(\varepsilon_{n}-\alpha T_{0}\right) \quad ; \quad N>0 \text { compression } \\
M_{n}(x)=-E I v_{n}^{\prime \prime} \\
V_{n}(x)=-\left(E I v_{n}^{\prime \prime}\right)^{\prime}+E A\left(\varepsilon_{n}-\alpha T_{0}\right) v_{n}^{\prime}
\end{array}\right\}
$$

Because of the first transversality condition, $v_{1}^{\prime \prime}(z)=0$, it follows from the second equation in $(4.10)$ that

$$
\lambda_{3}=0
$$


Thus, a concentrated reaction moment $\lambda_{3}$ does not exist at point $x=2$.

From the third equation in (4.11) it may be concluded, noting that $v_{1}^{\prime}(l)=0$, that at $x=l$ there acts a concentrated reaction force of magnitude

$$
\lambda_{2}=\left[\left(E I v_{1}^{\prime \prime}\right)^{\prime}\right]_{2}
$$

This reaction force occurs because of the use of the bending theory for the track-beam and the constraint condition $v_{a}(x) \equiv 0$. It represents a concentration of the contact pressure in the close vicinity of $x \geqq 2$

From the above derivations it follows that the equilibrium formulation of the track in the lateral plane consists of the nonlinear differential equations in (4.6) and (4.7), the three boundary conditions (4.8) at $x=0$, the two conditions (4.11) at $x=l_{0}$, and the five conditions at $x=\imath$, consisting of the three matching conditions in $\left(4.9^{\prime}\right)$ and the two conditions from (4.10)

$$
\begin{aligned}
& u_{l}^{\prime}(z)=u_{a}^{\prime}(z) \\
& v_{l}^{\prime \prime}(z)=0 \quad \text { (transversality condition) }
\end{aligned}
$$

Thus, 10 conditions for the determination of the 8 integration constants and the 2 unknown lengths, $l$ and $l_{0}$.

\subsubsection{Solution of Formulation for Shape I}

The differential equations in (4.6) and (4.7) are nonlinear. However, since the second equation in (4.6) when integrated yields

$$
\mathrm{EA}\left(\epsilon_{1}-\alpha \mathrm{T}_{0}\right)=\text { const }=-\widetilde{\mathbb{N}}_{t} \quad 0 \leqq \mathrm{x} \leqq 2
$$

the first equation in (4.6) reduces, for $E I=$ const, to

$$
E I v_{1}{ }^{i v}+\tilde{\mathbb{N}}_{t} v_{l}^{\prime \prime}=-\rho_{0} \quad 0 \leqq x \leqq Z
$$

a Zinear ordinary differential equation with constant coefficierts. 
This analytical feature makes it possible to solve the derived nonlinear formulation for the lateral buckling of the railroad track exactly and in closed form. It was utilized in [4] for the solution of the vertical track buckling problem.

For the track beam, the coefficient EI is constant, since in a railroad track the parameters of the rail-tie structure (such as the rail and tie characteristics, the gauge, the tie spacing, and the fastener type) usually do not vary.

According to (4.12), the left-hand side of eq. (4.15) is the axial force in the buckled region. It was denoted by $-\tilde{\mathbb{N}}_{t}$. Thus, the axial compression force in the buckled region is $\left(+\tilde{\mathbb{N}}_{t}\right)$ and is constant.

The general solution of eq. $(4.16)$ is

$$
v_{1}(x)=A_{1} \cos \lambda x+A_{2} \sin \lambda x+A_{3} x+A_{4}-\frac{\rho^{*}}{2 \lambda^{2}} x^{2}
$$

where

$$
\lambda=\sqrt{\frac{\tilde{N}_{t}}{E I}} \quad ; \quad \rho^{*}=\frac{\rho}{E I}
$$

Since for the considered problem $\tilde{\mathbb{N}}_{t}>0$, it follows that $\lambda$ is a real number. From the second and third conditions in (4.8) it follows that $A_{2}=A_{3}=0$. The constants $A_{1}$ and $A_{4}$ are obtained using the first two conditions in (4.9'). The resulting $v_{1}$ is

$$
v_{I}(x)=\frac{p^{*} l^{4}}{2(\lambda l)^{2}}\left[1-\frac{x^{2}}{Z^{2}}-\frac{2(\cos \lambda x-\cos \lambda l)}{\lambda l \sin \lambda l}\right]
$$

The length $Z$ is as yet an unknown quantity. It is obtained from the transversality condition in (4.10). Substituting (4.18) into this equation, it follows that it is satisfied when

$$
\operatorname{tg} \lambda z=\lambda Z
$$


The roots of this equation are

$$
\lambda z=0,4.493, \ldots . . . \cdot
$$

The first root corresponds to the trivial case. It may be shown that the second root corresponds to the symmetric deflection shape I, shown in Fig. 5. * This root will be used in the following.

It should be noted that the $v_{I}(x)$ expression in (4.18), with $\lambda z=4.493$, contains still one unknown; namely the axial force $\tilde{\mathbb{N}}_{t}$. For its determination we use the remaining equations of the above formulation (namely those in terms of $u$ ). They are: the second equation in (4.6) and (4.7), which are nonlinear, and the corresponding boundary conditions in $(4.8),\left(4.9^{\prime}\right),(4.10)$ and $(4.11)$.

Since for the track-beam $\mathrm{EA}=$ const and $\mathrm{v}_{\mathrm{a}}(\mathrm{x}) \equiv 0$, the second equation in (4.7) reduces to the linear equation

$$
\mathrm{EAu}_{\mathrm{a}}^{\prime \prime}=-r_{0} \quad z \leqq x \leqq z_{0}
$$

Its general solution is

$$
u_{a}(x)=-\left(\frac{r_{0}}{E A}\right) \frac{x^{2}}{2}+B_{1} x+B_{2}
$$

Using the first condition in (4.1I), $u_{e}\left(z_{0}\right)=0$, we obtain

$$
B_{2}=\left[\frac{r_{0}^{2}{ }_{0}^{2}}{2 E A}-B_{1} z_{0}\right]
$$

Thus

$$
u_{a}(x)=-\frac{r_{0}}{2 E_{A}}\left(x^{2}-z_{0}^{2}\right)+B_{I}\left(x-z_{0}\right)
$$

Instead of the second equation in (4.6) we utilize its first integral given in (4.15); namely the nonlinear differential equation of the first order

$$
E A\left(u_{1}^{\prime}+\frac{l}{2} v_{l}^{\prime 2}-\alpha T_{0}\right)=-\tilde{N}_{t} \quad 0 \leqq x \leqq l
$$

*

Because of $\left(4.17^{\prime}\right)$, the expression $\lambda l=4.493$ may also be written as $\widetilde{\mathbb{N}}_{t}=20.19 \mathrm{EI} / \mathrm{Z}^{2}$. Note that in a number of referencs $l=l / 2$. IIence $\tilde{\mathbb{N}}_{t}=80.7 \mathrm{II} / \mathrm{\ell}^{2}$. 
Since, at this point of the analysis, $v_{1}(x)$ is a known function and is given in (4.18), the above equation reduces to a linear differential equation. Rewriting eq. (4.15) as

$$
u_{1}^{\prime}(x)=\left(\alpha 1_{0}-\frac{\tilde{N}_{t}}{E A}\right)-\frac{1}{2} v_{1}^{2}(x)
$$

and integrating it from 0 to $x$, noting that according to $(4.8) u_{1}(0)=0$, we obtain

$$
u_{l}(x)=\left(\alpha T_{0}-\frac{\tilde{N}_{t}}{E A}\right) x-\frac{1}{2} \int_{0}^{x} v_{1}^{\prime 2}(x) d x
$$

The three unknowns in (4.21) and (4.23) $B_{l}, Z_{0}, \tilde{N}_{t}$ are determined in the following from the remaining two matching conditions at $l$ and the one at $\tau_{0}$.

Substituting expressions (4.21) and (4.22) into the matching condition $u_{1}^{\prime}(z)=u_{a}^{\prime}(z)$ and noting that according to $\left(4.9^{\prime}\right) v_{1}^{\prime}(z)=0$, we obtain

$$
B_{1}=\left(\alpha T_{0}-\frac{\tilde{N}_{t}}{E A}\right)+\frac{r_{0} 2}{E A}
$$

Thus

$$
u_{a}(x)=\left[\frac{r_{0}}{2 E A}(x+a-z)-\left(\alpha T_{0}-\frac{\tilde{N}_{t}}{E A}\right)\right]\left(z_{0}-x\right)
$$

Substituting the $u$ expressions from (4.23) and (4.25) into the matching condition $u_{l}(z)=u_{a}(z)$, we obtain

$$
\left(\alpha T_{0}-\frac{\tilde{N}_{t}}{E A}\right)(z+a)-\frac{1}{2} \int_{0}^{z} v_{1}^{2}(x) d x=\frac{r_{0} a^{2}}{2 E A}
$$

Evaluation of the integral term, noting (4.18) and (4.19), yields

$$
\int_{0}^{l} v_{l}^{\prime 2}(x) d x=\frac{5 z}{6}\left(\frac{\rho^{*} z}{\lambda^{2}}\right)^{2}=20.45 \times 10^{-4} \rho^{* 2} z^{7}
$$


With this expression eq. $(4.26)$ becomes

$$
\alpha T_{0}=\frac{\tilde{N}_{t}}{E A}+\frac{5 z}{12 Z_{0}}\left(\frac{\rho_{0} z}{\frac{N_{t}}{N_{t}}}\right)^{2}+\frac{r_{0}\left(l_{0}-l\right)^{2}}{2 \mathrm{EA} Z_{0}}
$$

Substituting the $u_{a}(x)$ expression given in (4.25) into the transversality condition in $(4.11), u_{a}^{\prime}\left(l_{0}\right)=0$, we obtain

$$
\left(\mathrm{EAaT}_{0}-\tilde{\mathbb{N}}_{t}\right)=r_{0}\left(z_{0}-z\right)
$$

Since $\mathrm{H}_{\mathrm{A}} \mathrm{A} \mathrm{T}_{0}=N_{t}$ is the axial compression force in the undeformed trackbeam, eq. (4.29) may also be written as

$$
\left(N_{t}-\tilde{N}_{t}\right)=r_{0}\left(z_{0}-z\right)
$$

Thus, the transversality condition at $x=l_{0}$ yields the equizibrium equation of the adjoining region in the axial direction, as shown in Fig. 7 .

The exact solution is thus obtained. The displacements at equilibrium are given as follows: $v_{1}(x)$ by (4.18), $u_{1}(x)$ by (4.23), $v_{a}(x) \equiv 0$, and $u_{a}(x)$ by $(4.25)$. The relationship between $T_{0}$ and $\tilde{\mathbb{N}}_{t}$ is given in (4.28), noting that according to $\left(4.19^{\prime}\right) \lambda 2=4.493$ for the symmetrical mode $I$, that $l_{0}$ is determined from (4.29), and that $\lambda^{2}=\tilde{N}_{t} /(E I)$.

To simplify the numerical evaluation it should be noted that in eq. (4.26) the unknown $a=\left(z_{0}-\tau\right)$ may be eliminated by utilizing eq. (4.29). The resulting equation is

$$
\left(\mathbb{N}_{t}-\tilde{N}_{t}\right)^{2}+2 \operatorname{Zr} 0_{0}\left(N_{t}-\tilde{N}_{t}\right)-E A r_{0} \int_{0}^{l} v_{1}^{2}(x) d x=0
$$

where $\mathbb{N}_{t}=E A \alpha T_{0}$. Solving this quadratic equation we obtain 


$$
\mathrm{EAaT}_{0}=\tilde{\mathbb{N}}_{t}+\operatorname{lr}\left\{\left\{-1 \pm \sqrt{1+\frac{E A}{l^{2} r_{0}} \int_{0}^{l} v_{i}^{2} \mathrm{dx}}\right\}\right.
$$

For a given track (thus, for known values of $E, A, I, \alpha, r_{0}, \rho_{0}$ ) the numerical evaluation of the obtained solution consists of the following steps: Choose a positive value for $\tilde{\mathbb{N}}_{t}$ and determine the corres-

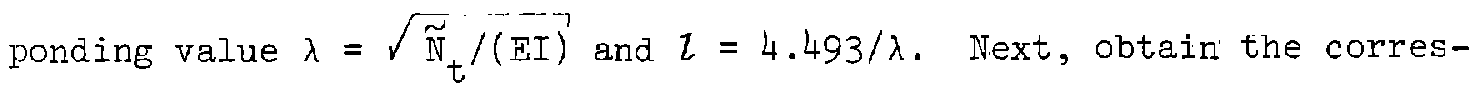
ponding $T_{0}$ value from $(4.31)$, noting ( 4.27$)$. The corresponding displacements are then given by (4.18), (4.23) and (4.25).

The numerical evaluation was performed for a track with 115 1b/yard rails on wooden cross-ties with cut-spike fasteners (of negligible rotational resistance). The following parameters were used:

$$
\begin{array}{lll}
A=145 \mathrm{~cm}^{2}\left(11.25 \mathrm{in}^{2}\right) & I=2 I_{r}=899 \mathrm{~cm}^{4}\left(21.6 \mathrm{in}^{4}\right) \\
\left.\Phi=2.1 \times 10^{6} \mathrm{~kg} / \mathrm{cm}^{2}\left(3 \times 10^{7} \mathrm{lb} / \mathrm{in}\right)^{2}\right) & \alpha=1.05^{\circ} \times 10^{-5} 1 / \mathrm{C}^{\circ} \\
\rho_{0}=600 \mathrm{~kg} / \mathrm{m}(402 \mathrm{lb} / \mathrm{ft}) & r_{0}=1000 \mathrm{~kg} / \mathrm{m}(670.8 \mathrm{lb} / \mathrm{ft})
\end{array}
$$

The corresponding graphs are shown in Fig. 8 (as dashed lines), noting that for shape $\mathrm{I}, \mathrm{v}_{\max }=\mathrm{v}(0)$. The obtained graphs are of the same type as the ones obtained for the much simpler track model analyzed in Ref. [5] (Fig. Il).

According to Fig. 8, for the used track parameters the safe temperature increase is $\mathrm{T}_{\mathrm{L}}=43.7^{\circ} \mathrm{C}$. Note that for any uniform temperature increase $\mathrm{T}_{\mathrm{O}}>\mathrm{T}_{\mathrm{L}}$ there correspond three states of equilibrium: The (stable) straight state, the (unstable) equilibrium state on branch $\mathrm{AL}$ and the (stable) equilibrium state on branch LB. Thus, when the track buckles at a temperature increase $T_{O}>T_{L}$ it will go over to the corresponding laterally deformed equilibrium configuration on branch LB. 

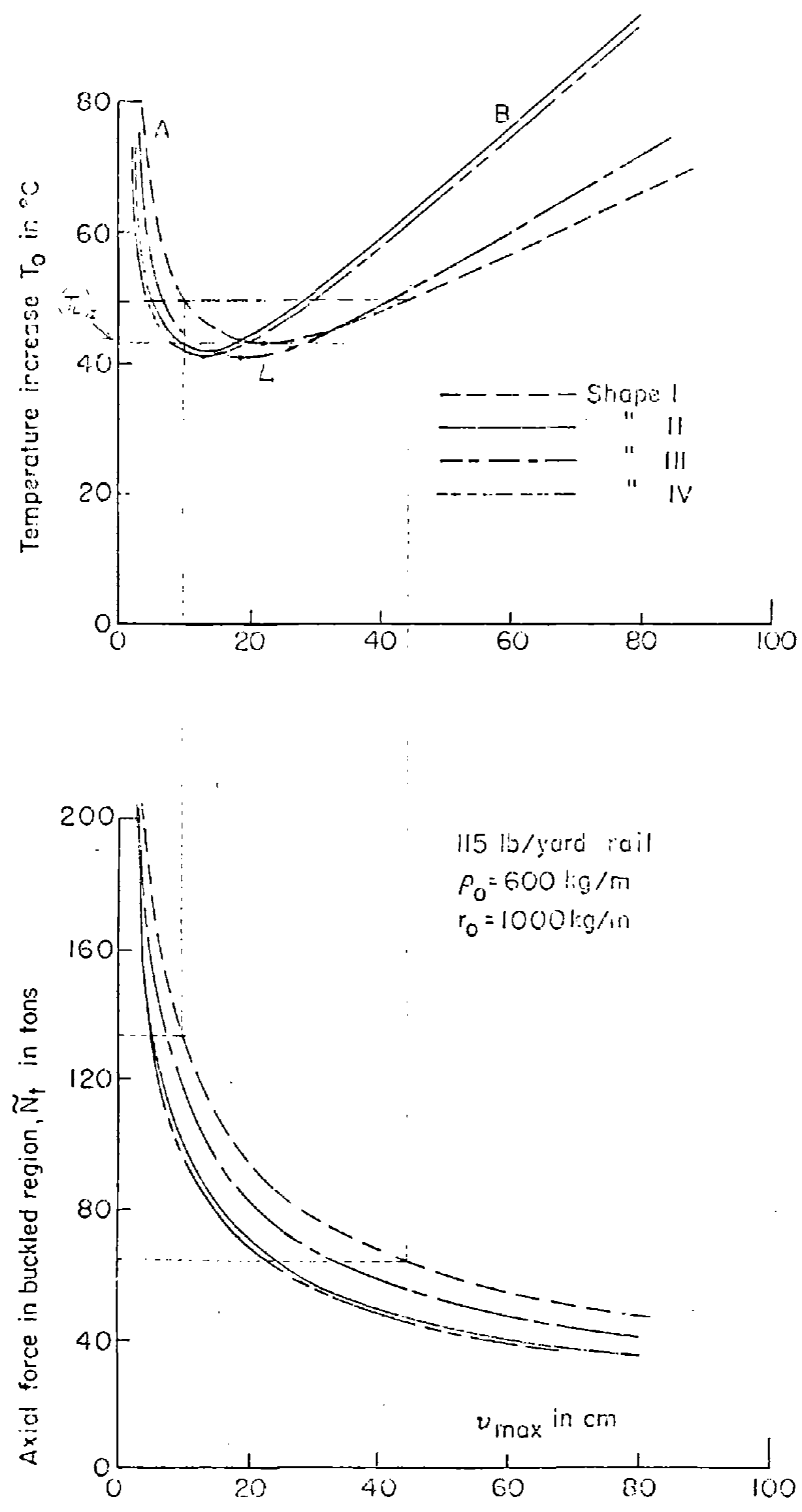

FIG. 8. COMPARISON OF POST-BUCKLIING EQUILIBRTUM BRAITCHES ANID THE CORRESPONDING AXIAL FORCES $\widetilde{\mathbb{N}}_{t}$, FOR SHAPES I TO IV 
In this connection note the large drop of the axial force due to buckling and the corresponding values for a and $l$ shown in Table 1 .

TABLE 1. CALCULATED TRACK DATA - SHAPE I

\begin{tabular}{|c|c|c|c|c|}
\hline $\begin{array}{l}\text { Temperature } \\
\text { increase } \\
\mathrm{T}_{0} \text { in }{ }^{\circ} \mathrm{C}\end{array}$ & $\begin{array}{l}\text { Axial force } \\
\text { in straight state } \\
\mathbb{N}_{t}=E_{A \alpha} T_{0} \text { in tons }\end{array}$ & $\begin{array}{l}\text { Axial force } \\
\text { in buckled region } \\
\tilde{\mathbb{N}}_{t} \text { in tons. }\end{array}$ & $\begin{array}{l}a=\frac{\mathbb{N}_{t}-\tilde{N}_{t}}{r_{0}} \\
\text { in meters }\end{array}$ & $\begin{array}{c}2 \\
\text { in meters }\end{array}$ \\
\hline$T_{L}=43.7$ & 139.7 & 90.0 & 49.7 & 6.5 \\
\hline$T=50.0$ & 160.0 & 62.8 & 97.2 & 7.8 \\
\hline
\end{tabular}

\subsection{ANALYSIS FOR ANTISYMMETRICAL DEFORMATION SHAPE II}

\section{2:1 Formulation of Problem}

The general form of the deformation shape II is shown in Fig. 5 . Also for its analysis the track consists of five regions, as for shape I. Because of the antisymmetry of shape II, it is sufficient to consider only the part for $\mathrm{x} \geqq 0$. The formulation is therefore identical to the one for shape I, except for the boundary conditions at $x=0$.

Thus, the differential equations for the track are given, as before, by (4.6) and (4.7). From eq. (4.5) it follows that the boundary conditions at $x=0$ are:

$$
v_{1}(0)=0 \quad ; \quad v_{1}^{\prime \prime}(0)=0 \quad ; \quad u_{1}(0)=0
$$

The conditions at $x=\imath$ and $x=\tau_{0}$ are the same as before. Namely

$$
\left.\begin{array}{ll}
v_{1}(z)=0 & v_{1}^{\prime}(z)=0 \\
u_{1}(z)=u_{a}(z) & u_{1}^{\prime}(z)=u_{a}^{\prime}(z) \\
v_{1}^{\prime \prime}(z)=0 & \text { (transversality condition) }
\end{array}\right\}
$$


and

$$
\left.\begin{array}{ll}
u_{a}\left(z_{0}\right)=0 & \\
u_{a}^{\prime}\left(z_{0}\right)=0 \quad \text { (transversality condition) }
\end{array}\right)
$$

\subsubsection{Solution of Formulation for Shape II}

Because the differential equations are the same as for shape I, it follows that the general solutions are the same. Namely:

$$
\begin{aligned}
& v_{1}(x)=A_{1} \cos \lambda x+A_{2} \sin \lambda x+A_{3} x+A_{4}-\frac{\rho^{*}}{2 \lambda^{2}} x^{2} \\
& u_{1}(x)=\left(a_{0}-\frac{\ddot{N}_{t}}{E A}\right) x-\frac{1}{2} \int_{0}^{x} v_{1}^{\prime}(x) d x \\
& v_{a}(x)=0 \\
& u_{a}(x)=-\frac{0}{2 E A}\left(x^{2}-z_{0}{ }^{2}\right)+B_{1}\left(x-z_{0}\right)
\end{aligned}
$$

The integration constants $\mathrm{A}_{3}$ to $\mathrm{A}_{4}$ are determined from the first two conditions in (4.32) and in (4.9').

They are:

$$
\begin{aligned}
& A_{1}=-\frac{\rho^{*}}{\lambda^{4}} \quad ; \quad A_{2}=\frac{0^{*}}{\lambda^{4}} \frac{(1-\cos \lambda I)+(\lambda I)^{2} / 2-\lambda I \sin \lambda I}{\lambda 2 \cos \lambda l-\sin \lambda I} \\
& A_{3}=\frac{0^{*}}{\lambda^{3}} \frac{(1-\cos \lambda l)+(\lambda \tau / 2 \cos \lambda z-\sin \lambda \tau) \lambda z}{\lambda 2 \cos \lambda 2-\sin \lambda 2} ; A_{4}=\frac{0^{*}}{\lambda^{4}}
\end{aligned}
$$

Substituting the obtained $v_{I}(x)$ into the transversality condition, $v_{1}^{\prime \prime}(Z)=0$, it follows that it is satisfied when

$$
2(1-\cos \lambda \tau)=\lambda 2 \sin \lambda \tau
$$


provided $\operatorname{tg} \lambda I \neq \lambda I$. Thus, the roots of this equation are

$$
\lambda \tau=2 \pi, 8.987, \ldots
$$

It may be shown that the first root corresponds to the antisymmetrical deformation shape II, shown in Fig. 5.

With $\lambda I=2 \pi$, the expressions for the integration constants simplify to

$$
\left.\begin{array}{lll}
A_{1}=-\frac{\rho * 2^{4}}{16 \pi^{4}} & ; & A_{2}=\frac{\rho^{*} 2^{4}}{16 \pi^{3}} \\
A_{3}=\frac{\rho^{*} z^{3}}{8 \pi^{2}} & ; & A_{4}=\frac{\rho^{*} z^{4}}{16 \pi^{4}}
\end{array}\right\}
$$

and $v_{1}(x)$ becomes

$$
v_{1}(x)=\frac{p^{*} l^{4}}{16 \pi^{4}}\left\{1-\cos \left(\frac{2 \pi x}{l}\right)+\pi \sin \left(\frac{2 \pi x}{2}\right)-2 \pi^{2}\left[\left(\frac{x}{l}\right)^{2}-\frac{x}{l}\right]\right\}
$$

The above expression $v_{1}(x)$ contains still one unknown; namely the axial force $\tilde{N}_{t}$. For its determination we utilize the equations for $u(x)$ of the above formulation. Since they are the same as those used in the analysis of shape I, the steps are also the same. Therefore, the additional equation needed for the determination of $\tilde{N}_{t}$ is

$$
E A T_{0}=\tilde{N}_{t}+\operatorname{lr}_{0}\left\{-1+\sqrt{1+\frac{F A}{22 r_{0}} \int_{0}^{2} v_{1}^{\prime 2} d x}\right\}
$$

where $v_{I}(x)$ is given by $(4.35)$ and the corresponding integral is

$$
\int_{0}^{\tau} v_{1}^{\prime 2} d x=17.430 \times 10^{-5} p * 2 \tau^{7}
$$

Also for shape II, the length of the adjoining region is 


$$
a=\left(E_{0} T_{0}-\tilde{N}_{t}\right) / r_{0}
$$

The exact solution for the deformation shape II is thus obtained. It was numerically evaluated for the same track parameters as used for shape $I$. The results are shown in Fig. 8, as solid lines. $v_{\max }$ was calculated by first forming $d v_{1} / d x=0$ which yielded $x / 2=0.3464$ and then by substituting this value into $v_{1}(x)$.

The obtained graphs are very similar to the corresponding graphs of shape I. The drop of the axial force in the buckled region and the corresponding a and $Z$ values, at $T_{0} \geq T_{L}$, are given in Table 2 .

TABLE 2. CALCULATED TRACK DATA - SHAPE II

\begin{tabular}{|c|c|c|c|c|}
\hline $\begin{array}{l}\text { Teinperature } \\
\text { increase } \\
\mathrm{T}_{0} \text { in }{ }^{\circ} \mathrm{C}\end{array}$ & $\begin{array}{c}\text { Axial force } \\
\text { in straight state } \\
N_{t}=E A \alpha T_{0} \text { in tons }\end{array}$ & $\begin{array}{l}\text { Axial force } \\
\text { in buckled region } \\
\mathbb{N}_{t} \text { in tons }\end{array}$ & $\begin{array}{l}a=\frac{\mathbb{N}_{t}-\tilde{N}_{t}}{r_{0}} \\
\text { in meters }\end{array}$ & ${ }^{2}$ in meters \\
\hline$T_{L}=42.0$ & 134.3 & 89.0 & 45.3 & 9.2 \\
\hline$T=50.0$ & 160.0 & 58.0 & 102,0 & 11.3 \\
\hline
\end{tabular}

\subsection{ANALYSIS FOR SYMMETRICAL DEFORMATION SHAPE III*}

\subsubsection{Formulation of Problem}

The general form of shape III is shown in Fig. 5. For the following analysis the track consists of seven regions, since the buckled zone now contains three regions (instead of one).

* The research for sections 4.3 and 4.4 was supported by NSF Grant ENG74-19030. They areincluded here for the sake of completeness of presentation. 
Because of the assumed symmetry of the buckled track, eq.

becomes

$$
\begin{aligned}
& \delta \int_{0}^{Z_{1}} F_{1} d x+\int_{l_{1}}^{l} F_{2} d x+\int_{l}^{Z_{0}} F_{a} d x+\int_{l_{0}}^{\infty} F_{\infty} d x+ \\
& \left.+\lambda_{2} v_{a}(z)+\lambda_{3} v_{a}^{\prime}(z)\right\}=0
\end{aligned}
$$

where $F_{I}, F_{a}, F_{\infty}$ are given in $(4.2)$,

$$
\mathrm{F}_{2}=\frac{1}{2}\left[\mathrm{EA}\left(\varepsilon_{2}-\alpha \mathrm{T}_{0}\right)^{2}+\mathrm{EIV}_{2}^{\prime \prime 2}\right]-n(x-\tau) r_{0} u_{2}-\rho_{0} \mathrm{v}_{2}
$$

subject to the constraint conditions (4.3') and (4.3").

Proceeding as for deformation shape $I$, noting that $l_{I}, Z$ and $I_{0}$ are variable end points, the following formulation results:

The nonlinear differential equations:

$$
\begin{aligned}
& \left(E I v_{1}^{\prime \prime}\right)^{\prime \prime}-\left[E A\left(\varepsilon_{1}-\alpha T_{0}\right) v_{1}^{\prime}\right]^{\prime}=-\rho_{0} \\
& {\left[\mathrm{EA}\left(\varepsilon_{1}-\alpha \mathrm{T}_{0}\right)\right]^{\prime}=0 \quad 0 \leq \mathrm{x} \leqq z_{1}} \\
& \begin{array}{r}
\left(E I v_{2}^{\prime \prime}\right)^{\prime \prime}-\left[E A\left(\varepsilon_{2}-\alpha T_{0}\right) v_{2}^{\prime}\right]^{\prime}=+\rho_{0} \\
{\left[E A\left(\varepsilon_{2}-\alpha T_{0}\right)\right]^{\prime}=0}
\end{array} \mid \quad Z_{1} \leqq x \leqq Z \\
& \left.\begin{array}{rl}
\lambda_{1} & =0 \\
{\left[\mathrm{EA}\left(\varepsilon_{\mathrm{a}}-\alpha \mathrm{T}_{0}\right)\right]^{\prime}} & =-\mathrm{r}_{0}
\end{array}\right\} \quad z \leqq \mathrm{x} \leqq z_{0}
\end{aligned}
$$

where

$$
E_{n}=u_{n}^{\prime}+\frac{1}{2} v_{n}^{\prime 2} \quad n=1,2, a
$$


the constraint equations

$$
u_{\infty}(x) \equiv 0 \quad ; \quad v_{\infty}(x) \equiv 0
$$

and the boundary and matching conditions

$$
\left.\begin{array}{cc}
v_{1}^{\prime}(0)=0 ; & v_{1}^{\prime \prime \prime}(0)=0 \quad ; \quad u_{1}(0)=0 \\
v_{1}\left(z_{1}\right)=v_{2}\left(z_{1}\right) & v_{1}^{\prime \prime}\left(z_{1}\right)=v_{2}^{\prime \prime}\left(z_{1}\right) \\
v_{1}^{\prime}\left(z_{1}\right)=v_{2}^{\prime}\left(z_{1}\right) & v_{1}^{\prime \prime \prime}\left(z_{1}\right)=v_{2}^{\prime \prime \prime}\left(z_{1}\right) \\
u_{1}\left(z_{1}\right)=u_{2}\left(z_{1}\right) & u_{1}^{\prime}\left(z_{1}\right)=u_{2}^{\prime}\left(z_{1}\right) \\
v_{1}\left(z_{1}\right)=0 & {\left[\text { thus, also } v_{2}\left(z_{1}\right)=0\right]} \\
v_{2}(z)=0 & v_{2}^{\prime}(z)=0 \\
u_{2}(z)=u_{a}(z) & u_{2}^{\prime}(z)=u_{a}^{\prime}(z) \\
v_{2}^{\prime \prime}(z)=0 &
\end{array}\right\}
$$

and

$$
u_{a}^{\prime}\left(z_{0}\right)=0 \quad ; \quad u_{a}\left(z_{0}\right)=0
$$

Thus, 17 conditions for the determination of the 14 integration constants and the 3 unknown lengths $Z_{I}$, $Z$ and $Z_{0}$

\subsubsection{Solution of Formulation for Shape III}

Integrating once the second equation in (4.38) and in (4.39), we may write

$$
\begin{array}{ll}
E A\left(\varepsilon_{1}-\alpha T_{0}\right)=\text { const. }=-\tilde{N}_{t 1} & 0 \leqq x \leqq l_{I} \\
E A\left(\varepsilon_{2}-\alpha T_{0}\right)=\text { const. }=-\tilde{\mathbb{N}}_{t 2} & z_{1} \leqq x \leqq 2
\end{array} \mid
$$


Noting the matching conditions for $u^{\prime}$ and $v^{\prime}$ in (4.43) it follows that

$$
\tilde{N}_{t I}=\tilde{N}_{t 2}=\tilde{N}_{t}
$$

Thus, for $\mathrm{EI}=$ const., the first equation in (4.38) and in (4.39) reduce to the linear differential equations with constant coefficients

$$
\begin{array}{ll}
E I v_{1}^{i v}+\tilde{N}_{t} v_{I}^{\prime \prime}=-\rho_{0} & 0 \leqq x \leq \tau_{I} \\
E I v_{2}^{i v}+\tilde{N}_{t} v_{2}^{\prime \prime}=+\rho_{0} & z_{1} \leq x \leq z
\end{array} ;
$$

Their general solutions are

$$
\left.\begin{array}{l}
v_{1}(x)=A_{1} \cos \lambda x+A_{2} \sin \lambda x+A_{3} x+A_{4}-\frac{\rho^{*}}{2 \lambda^{2}} x^{2} \\
v_{2}(x)=A_{5} \cos \lambda x+A_{6} \sin \lambda x+A_{7} x+A_{8}+\frac{\rho^{*}}{2 \lambda^{2}} x^{2}
\end{array}\right\}
$$

Using the 8 boundary and matching conditions for $v$ in (4.42), (4.43) and (4.44), the constants $A_{1}$ to $A_{8}$ are obtained as:

$$
\begin{aligned}
& A_{1}=\frac{2 \rho * I^{4}}{(\lambda z)^{4}}\left[\psi-\cos \lambda z_{1}\right] \quad ; \quad A_{2}=A_{3}=0 \\
& A_{4}=\frac{\rho^{*} Z^{4}}{2(\lambda z)^{4}}\left\{\left(\lambda z_{1}\right)^{2}-4\left[\psi-\cos \lambda z_{1}\right] \cos \lambda z_{1}\right\} \\
& A_{5}=\frac{2 \rho * l^{4}}{(\lambda l)^{4}} \psi ; A_{6}=\frac{2 \rho * l^{4}}{(\lambda l)^{4}} \sin \lambda z_{1} ; A_{7}=-\frac{2 \rho * l^{4}}{(\lambda l)^{3} z} \lambda l_{1} \\
& A_{8}=\frac{20 * l^{4}}{(\lambda z)^{4}}\left[-\psi \cos \lambda l-\sin \lambda l \sin \lambda z_{1}+\lambda z_{1} \lambda z-(\lambda z)^{2} / 4\right]
\end{aligned}
$$

where

$$
\psi=\frac{1}{\sin \lambda z}\left(\cos \lambda z \sin \lambda z_{I}-\lambda z_{1}+\lambda z / 2\right)
$$


For the determination of $z_{I}$ and $Z_{\text {we }}$ utilize the two transversality conditions $v_{2}\left(z_{1}\right)=0$ and $v_{2}^{\prime \prime}(z)=0$, and obtain

$$
\begin{aligned}
& A_{5} \cos \lambda Z_{1}+A_{6} \sin \lambda z_{1}+A_{7} z_{1}+A_{8}+\rho * Z^{4}\left(\lambda z_{1}\right)^{2} /\left[2(\lambda z)^{4}\right]=0 \\
& A_{5} \cos \lambda z+A_{6} \sin \lambda z-\rho * Z^{4} /(\lambda z)^{4}=0
\end{aligned}
$$

where $A_{5}$ to $A_{8}$ are given above. The lowest roots $\lambda z_{1}$ and $\lambda l$ of the two simultaneous algebraic equations in (4.50), which correspond to the shape III shown in Fir. 5, were found using a numerical trial and error approach. They are

$$
\lambda z_{I}=2.92 \quad \vdots \quad \lambda z=7.55
$$

Thus, for shape III, $2 / \tau_{1}=2.6$.

For these roots the integration constants $A_{1}$ to $A_{8}$ become

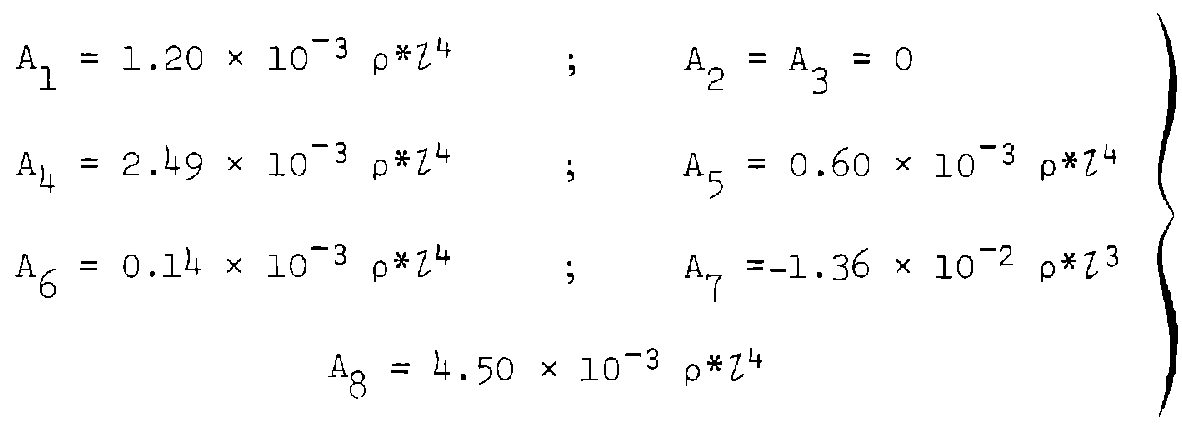

The expressions for $v_{1}(x)$ and $v_{2}(x)$ contain still one unknown; namely the axial force $\tilde{\mathbb{N}}_{t}$. This unknown is determined in the following from the equations for $u(x)$ of the above formulation, in a similar manner as done for shape $I$.

From the equations in (4.46) it follows, noting (4.46'), that

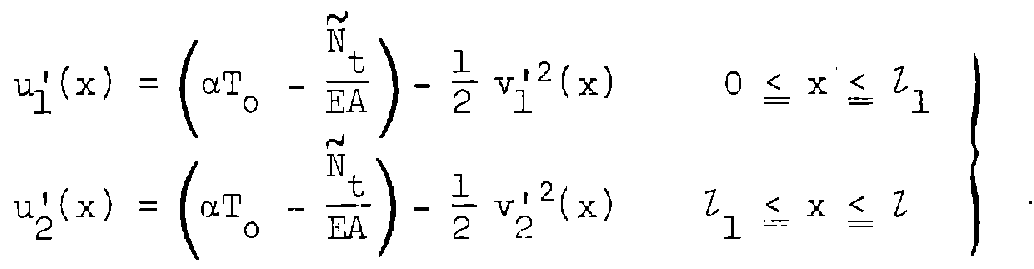


Integrating the first equation from 0 to $x$ we obtain, noting that $u_{1}(0)=0$

$$
u_{1}(x)=\left(\alpha T_{0}-\frac{\tilde{N}_{t}}{E A}\right) x-\frac{1}{2} \int_{0}^{x} v_{1}^{2} d x
$$

Integrating the second equation in (4.51) from $z_{1}$ to $x$ we obtain

$$
u_{2}(x)=u_{2}\left(z_{1}\right)+\left(\alpha T_{0}-\frac{\tilde{N}_{t}}{E A}\right)\left(x-z_{1}\right)-\frac{1}{2} \int_{z_{1}}^{x} v_{2}^{\prime 2} d x
$$

The differential equation for $u_{a}$, in (4.40), is the same as the one in (4.7) for shape I. Also the corresponding boundary and matching conditions are the same, as for shape $I$, except that $u_{1}(x)$ is replaced by the adjoining $u_{2}(x)$. Thus, the solution of the second equation in (4.40) subjected to the conditions $u_{a}\left(z_{0}\right)=0$ and $u_{2}^{\prime}(z)=u_{a}^{\prime}(z)$ is, as before,

$$
u_{a}(x)=\left[\frac{r_{0}}{2 E A}(x+a-z)-\left(\alpha T_{0}-\frac{\tilde{N}_{t}}{E A}\right)\right]\left(z_{0}-x\right)
$$

From the matching condition $u_{1}\left(z_{1}\right)=u_{2}\left(z_{1}\right)$ we obtain

$$
u_{2}\left(z_{1}\right)=\left(\alpha T_{0}-\frac{\tilde{N}_{t}}{E A}\right) z_{1}-\frac{l}{2} \int_{0}^{\tau_{I}} v_{1}^{\prime 2} d x
$$

and from the matching condition $u_{2}(z)=u_{a}(l)$ the relation

$$
\left(a \mathrm{~T}_{0}-\frac{\tilde{N}_{t}}{\mathrm{EA}}\right)(z+a)-\frac{1}{2}\left[\int_{0}^{l} v_{1}^{\prime 2} \mathrm{dx}+\int_{l_{1}}^{l} v_{2}^{\prime 2} \mathrm{dx}\right]=\frac{\mathrm{r}_{0} \mathrm{a}^{2}}{2 \mathrm{EA}}
$$

Equation (4.55) is the additional equation needed for the determination of $\tilde{\mathbb{N}}_{t}$. Substituting the $u_{a}(x)$ expression given above, into the condition $u_{a}^{\prime}(l)=0$ we obtain, as before, 


$$
\left(\mathbb{N}_{t}-\tilde{N}_{t}\right)=r_{a} a
$$

where $a=\left(z_{0}-l\right)$. Next, we eliminate the variable a from eq. (4.55) by using ( $\left.4.29^{\prime}\right)$. The resulting equation may be written as

$$
\left(\mathbb{N}_{t}-\tilde{N}_{t}\right)^{2}+2 \operatorname{lr}\left(N_{t}-\tilde{N}_{t}\right)-\operatorname{EAr}\left[\int_{0}^{l} v_{I}^{\prime 2} d x+\int_{l_{I}}^{l} v_{2}^{\prime 2} d x\right]=0
$$

or, in solved form,

$$
\operatorname{EA\alpha T} T_{0}=\tilde{N}_{t}+\operatorname{lr}\left\{-1+\sqrt{1+\frac{E A}{l^{2} r_{0}}\left[\int_{0}^{l} v_{i}^{\prime 2} d x+\int_{l_{1}}^{l} v_{2}^{\prime 2} d x\right]}\right\}
$$

The integral expressions which appear in (4.57) were evaluated, noting eqs. $(4.48)$ and $\left(4.49^{\prime}\right)$ and that according to $\left(4.50^{\prime}\right), l_{1} / l_{1}=2.6$. They are

$$
\left.\begin{array}{l}
\int_{0}^{l} v_{1}^{\prime 2} d x=3.10 \times 10^{-2} \rho * 2 z_{I}^{7} \\
\int_{I_{1}}^{l} v_{2}^{\prime 2} d x=6.32 \times 10^{-6} \rho * 2 I^{7}
\end{array}\right\}
$$

The solution for shape III is thus obtained. It was numerically evaluated for the track parameters used before. The results are shown in Fig. 5 as dash-dot-dash lines, noting that for the present case $\mathrm{v}_{\max }=\mathrm{v}_{1}(0)$.

The drop of the axial force in the buckled region and the corresponding values of $a, l_{1}$, and $l$, at $T_{0} \geq T_{L}$, are given in Table 3 . 
TABLE 3. CALCULATED TRACK DATA - SHAPE III

\begin{tabular}{|c|c|c|c|c|c|}
\hline $\begin{array}{c}\text { Temperature } \\
\text { increase } \\
\mathrm{T}_{0} \text { in }{ }^{\circ} \mathrm{C}\end{array}$ & $\begin{array}{c}\text { Axial force } \\
\text { straight state } \\
\mathrm{N}_{\mathrm{t}}=\mathrm{EA \alpha T} \text { tons }\end{array}$ & $\begin{array}{c}\text { Axial force } \\
\text { buckled region } \\
\tilde{N}_{t} \text { tons }\end{array}$ & $\begin{array}{c}\mathrm{N}_{\mathrm{t}}-\tilde{\mathrm{N}}_{\mathrm{t}} \\
\mathrm{r}_{0} \\
\text { meters }\end{array}$ & $\begin{array}{c}\tau_{I} \\
\text { meters }\end{array}$ & $\begin{array}{c}\tau \\
\text { meters }\end{array}$ \\
\hline $\mathrm{T}_{\mathrm{L}}=41.2$ & 131.8 & 88.8 & 43.0 & 4.3 & 11.0 \\
$\mathrm{~T}=50.0$ & 160.0 & 56.5 & 103.5 & 5.3 & 13.8 \\
\hline
\end{tabular}

4.4 ANALYSIS FOR ANTISYMMETRICAL DEFORMATION SHAPE IV

4.4.1 Formulation of Problem

The general form of shape IV is shown in Fig. 5. For its analysis the track consists of seven regions, as for shape III. Because of the antisymmetry of shape IV, it is sufficient to consider only the part for $x \geqq 0$. Therefore, the formulation for shape IV is identical to the one derived for shape III; except for the boundary conditions at $x=0$. These three boundary conditions are those of shape. II and are stated in eq. (4.32).

\subsubsection{Solution of Formulation for Shape IV}

Because the differential equations are the same as for shape III, it follows that the general solutions are also the same. Namely

$$
\begin{aligned}
& v_{1}(x)=A_{1} \cos \lambda x+A_{2} \sin \lambda x+A_{3} x+A_{4}-p^{*} x^{2} /\left(2 \lambda^{2}\right) \\
& v_{2}(x)=A_{5} \cos \lambda x+A_{6} \sin \lambda x+A_{7} x+A_{8}+p^{*} x^{2} /\left(2 \lambda^{2}\right) \\
& v_{a}(x) \equiv 0 \quad ; \quad v_{\infty}(x) \equiv 0
\end{aligned}
$$

The integration constants $A_{1}$ to $A_{8}$ for shape $i v$ are: 


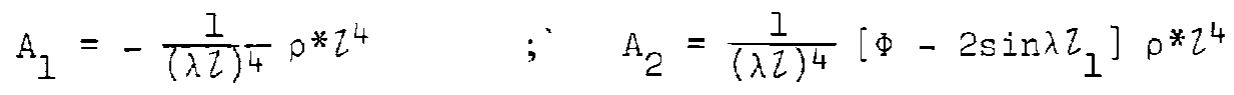

$$
\begin{aligned}
& A_{3}=\frac{1}{(\lambda z)^{3}}\left[\theta \sin \lambda z+2 \lambda z_{1}-\lambda z-\Phi \cos \lambda z\right] \rho^{*} z^{3} \quad ; \quad A_{4}=\frac{1}{(\lambda l)^{4}} \rho^{*} z^{4} \\
& A_{5}=\frac{\theta}{(\lambda \tau)^{4}} \rho * 2^{4} \quad ; \quad A_{6}=\frac{\Phi}{(\lambda \tau)^{4}} \rho * 2^{4} \\
& A_{7}=\frac{1}{(\lambda Z)^{3}}[\theta \sin \lambda z-\lambda z-\Phi \cos \lambda z] \rho^{*} z^{3} \\
& A_{8}=-\frac{I}{(\lambda l)^{4}}\left[\theta(\cos \lambda \tau+\lambda I \sin \lambda \tau)+\Phi(\sin \lambda z-\lambda Z \cos \lambda \tau)+\frac{\lambda^{2} Z^{2}}{2}\right] \rho^{*} \tau^{4}
\end{aligned}
$$

where

$$
\begin{aligned}
& \theta=2 \cos \lambda z_{1} \cdots I \\
& \Phi=\frac{\left(\lambda z_{1} \sin \lambda \tau+\cos \lambda z_{1}\right) \theta+\lambda z_{1}\left(\frac{3}{2} \lambda z_{1}-\lambda \tau_{1}-\frac{1}{\lambda \tau_{1}}\right)}{\left(\lambda z_{1} \cos \lambda \tau_{-}-\sin \lambda \tau_{1}\right)}
\end{aligned}
$$

The two conditions for the determination of $l_{1}$ and $l$ are the same as those for shape III and are given in (4.50). For the $A_{n}$ constants fiven above, the lowest roots of these two equations, which correspond to shape IV were found to be

$$
\lambda z_{1}=5.31 \quad ; \quad \lambda z=8.54
$$

Thus for shape IV, $I / \tau_{1}=1.6$.

For the above roots the constants $A_{1}$ to $A_{8}$ become

$$
\begin{aligned}
& A_{1}=-0.19 \times 10^{-3} \rho_{0} Z^{4} ; A_{2}=0.57 \times 10^{-3} p^{*} z^{4} ; A_{3}=4.89 \times 10^{-}{ }^{3} * z^{3}
\end{aligned}
$$

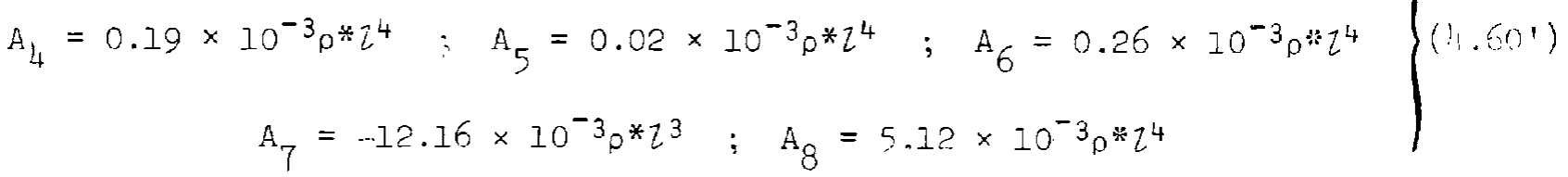

The remaining derivations are the same as for shape III. The results are: 


$$
\begin{aligned}
& u_{1}(x)=\left(\alpha T_{0}-\frac{\tilde{N}_{t}}{E A}\right) x-\frac{1}{2} \int_{0}^{x} v_{1}^{\prime 2} d x \\
& u_{2}(x)=\left(\alpha T_{0}-\frac{\tilde{N}_{t}}{E A}\right) x-\frac{1}{2}\left[\int_{0}^{\tau_{1}^{1}} v_{1}^{\prime 2} d x+\int_{z_{1}}^{x} v_{2}^{\prime 2} d x\right] \\
& \left(N_{t}-\tilde{N}_{t}\right)=r_{a} a
\end{aligned}
$$

and the equation for the determination of $\tilde{\mathbb{N}}_{t}$

$$
E A \alpha T_{0}=\tilde{N}_{t}+2 r_{0}\left\{-1+\sqrt{1+\frac{E A}{l^{2} r_{0}}\left[\int_{0}^{l} v_{1}^{\prime 2} d x+\int_{l_{1}}^{2} v_{2}^{\prime 2} d x\right]}\right\}
$$

The integral expressions which appear in the above equations were evaluated noting $(4.59)$ and $\left(4.50^{\prime}\right)$. They are, noting that $2 / z_{1}=1.6$, $\int_{0}^{l} v_{1}^{1} \mathrm{~d} x=5.49 \times 10^{-4} \rho * 2 z_{1}^{7} ; \int_{Z_{1}}^{z} v_{1}^{12} \mathrm{dx}=1.91 \times 10^{-7} \rho * 2 z^{7}$

The solution for shape.IV is thus obtained. The results of the numerical evaluation is shown in Fig. 5 as dash-dot-dot-dash lines. $v_{\max }$ was calculated by first forming $\mathrm{dv}_{1} / \mathrm{dx}=0$ which yielded $\mathrm{x} / \mathrm{L}_{1}=0.40$ and then by substituting this value into $v_{1}(x)$.

The drop of the axial force in the buckled region and the corresponding values for $a, z_{I}$ and $z$, at $T_{0} \geq T_{L}$, are given in Table 4 .

TABLE 4. CALCULATED TRACK DATA - SHAPE IV

\begin{tabular}{|c|c|c|c|c|c}
\hline $\begin{array}{c}\text { Temperature } \\
\text { increase } \\
\mathrm{T}_{0} \text { in }{ }^{\circ} \mathrm{C}\end{array}$ & $\begin{array}{c}\text { Axial force } \\
\text { straight state } \\
\mathrm{N}_{\mathrm{t}}=\mathrm{EAaT} \text { tons }\end{array}$ & $\begin{array}{c}\text { Axial force } \\
\text { buckled region } \\
\tilde{\mathrm{N}}_{\mathrm{t}} \text { tons }\end{array}$ & $\begin{array}{c}\mathrm{a}=\frac{\mathrm{N}_{\mathrm{t}}-\tilde{\mathrm{N}}_{\mathrm{t}}}{\mathrm{r}_{\mathrm{O}}} \\
\text { meters }\end{array}$ & $\begin{array}{c}\tau_{I} \\
\text { meters }\end{array}$ & $\begin{array}{c}\tau \\
\text { meters }\end{array}$ \\
\hline $\mathrm{T}_{\mathrm{L}}=41.0$ & 131.2 & 88.0 & 43.2 & 7.8 & 12.5 \\
$\mathrm{~T}=50.0$ & 160.0 & 56.3 & 103.7 & 9.7 & 1.5 .6 \\
\hline
\end{tabular}




\subsection{REMARKS ON OBTAINED RESUTTS}

A comparison of the post-buckling equilibrium branches, and the corresponding axial forces, shown in Fig. 8, reveals that the results for shape I to IV are very close, in particular with regard to the $T_{L}$-value.

A graphical comparison of the stable lateral displacements $\mathrm{v}$ for the $115 \mathrm{lb} /$ yard track at $\mathrm{T}_{0}=50^{\circ} \mathrm{C}$ is shown in $\mathrm{Fig}$. 5. In each of the four graphs the vertical scales the horizontal scales are the same. The shown wave lengths* and amplitudes are of the order observed in tests and discussed in [1]. Note, that according to the above tables the a-values are several times larger than the corresponding $Z$-values.

From Fig. 5 it follows that as more lateral waves are included in the analysis (shapes III and IV), the length of track affected by buckling* $2 l_{0}=2(Z+a)$, increases noticeably. This is not the case, however, in the actual problem. The increase of $2 l_{0}$ in Fig. 5 is caused by neglecting the axial resistance $r_{0}$ in the laterally buckled region, thus also in region $l_{1} \leqq x \leqq l$; a practice adopted by all investigators who determined postbuckling equilibrium branches for shapes III and/or IV.

The above finding suggests that for shapes III, IV or higher, the resistance $r$ should be included at least for $x>l_{1}$. The resulting formulation for shape III or IV remains the same as derived above, except for the second differential equation in (4.39) which becomes

$$
\left[\mathrm{EA}\left(\varepsilon_{2}-\alpha \mathrm{T}_{0}\right)\right]^{\prime}=-r \quad z_{1} \leqq \mathrm{x} \leq l
$$

It is anticipated that the effect of this correction on $T_{L}$ will be relatively small. For practical purposes the use of the results based on shapes II and III appears to be sufficient.

Note that $\mathrm{x}$ is a Lagrange variable and that $\mathrm{v}(\mathrm{x})$ is only the lateral component of the displacement vector. For example, the length of the buckled region is not $2 Z$, but $2[Z+u(Z)]$, although for the problems under consideration $u(l) \ll z$. 


\section{COMPARISON WITH RESULTS OF OTHER INVESTIGATORS}

A review of the analyses of thermal track buckling in the lateral plane was recently presented by Kerr [I]. One finding of this survey was that only a small number of the published analyses, namely those which took into account the drop of the axial force $\mathbb{N}_{t}$ in the buckled region, are conceptually correct. However, these few analyses, although based on the same fundamental assumptions (such as the replacement of the track by an elastic beam in bending, and the assumption that the axial and lateral resistances are constants) utilized different methods of solution with an unknown effect on the accuracy of the final results.

In this section the well known analyses of Martinet [8], Mishchenko [9], and Numata [10], which represent the different methods of solution, are briefly discussed and the obtained results are compared with those derived in the present paper.

Martinet [8] described the lateral response of the buckled track region by the linear differential equation of classical beam theory

$$
E I \frac{d^{4} v}{d x^{4}}+\widetilde{N}_{t} \frac{d^{2} v}{d x^{2}}= \pm \rho_{0}
$$

and used, at $x=l_{I}$ and $l$, the same boundary conditions as derived in the present paper. Since the linear differential equation for $v$, for example (4.16), which was obtained from the nonlinear equations in (4.6), is identical with eq. (5.1), the resulting solutions for the expressions $v$ are also the same. For the determination of the unknown axial force $\tilde{N}_{t}$, Martinet set up a separate compatibility equation for axial displacements at the juncture of the buckled and adjoining regions. For 
shapes I and II he obtained an expression which is identical with eq. (4.31). For shape III his compatibility equation is identical with eq. (4.57).

It is indeed noteworthy that, althogh Martinet used, a priori, a Zinear differential equation for $\mathrm{v}$ and derived the compatibility equation, heuristically, not making a distinction between Euler and Lagrange coordinates etc., he obtained results for shapes I, II and III which are the same as the corresponding results derived in the present paper. (In this connection refer to the corresponding questions raised by Kerr [1]].) Since in the present paper the formulation for the entire track was obtained in a unified and consistent manner and the obtained solutions of the resulting nonlinear formulations are exact, it may be concluded that the objections raised by Mishchenko ([10] pp. 64-65) regarding the accuracy of Martinet's solution are not valid.

Mishchenko [9] and Numata [10] used different variants of the energy approach. The effect of the drop of $\mathrm{N}_{t}$ to $\tilde{\mathbb{N}}_{t}$ (for which Martinet used a displacement compatibility equation) Mishchenko took into consideration in the expression of the total potential energy

$$
\Pi=\pi(f, z)
$$

where $f$ is an amplitude of lateral deflections and $2 l$ is the length of the buckled region, and by a displacement compatibility equation. The equilibrium relations Mishchenko obtained from the conditions 


$$
\frac{\partial \Pi}{\partial f}=0 \quad ; \quad \frac{\partial \Pi}{\partial t}=0
$$

Approximating shape I by the expression *

$$
v_{l}(x)=0.294 \times f \times\left(\cos \frac{4.492 x}{\imath}-2.190 \frac{x^{2}}{l^{2}}+2.407\right)
$$

where $f=v_{1}(0)$, the equilibrium equations obtained by Mishchenko are

$$
\left.\begin{array}{l}
2.77 \frac{\tilde{N}_{t} f}{\tau}-33.56 \frac{E I f}{\tau^{3}}-0.858 \rho_{0} z=0 \\
\frac{\left(\mathbb{N}_{t}-\tilde{N}_{t}\right)^{2}}{2 \mathrm{EA}}-0.692 \frac{\tilde{N}_{t} f^{2}}{l^{2}}+25.17 \frac{E I f^{2}}{l^{4}}-0.429 \mathrm{fo}_{0}=0
\end{array}\right\}
$$

and the derived compatibility relation may be written as

$$
\left(N_{t}-\tilde{N}_{t}\right)^{2}+2 \operatorname{Zr}{ }_{0}\left(N_{t}-\tilde{N}_{t}\right)-1.384 \frac{\operatorname{EAr}_{0} f^{2}}{l}=0
$$

Approximating shape II by two expressions, each valid in a different region, Mishchenko obtained the equilibrium equations

$$
\left.\begin{array}{l}
11.06 \frac{\tilde{N}_{t} f}{l^{2}}-254.4 \frac{E I f}{l^{3}}-1.012 \rho_{0} z=0 \\
\frac{\left(N_{t}-\tilde{N}_{t}\right)^{2}}{2 E A}-2.764 \frac{\tilde{N}_{t} f^{2}}{l^{2}}+190.8 \frac{E I f^{2}}{l^{4}}-0.506 \rho_{0} f=0
\end{array}\right\}
$$

and the corresponding compatibility equation

$$
\left(N_{t}-\tilde{N}_{t}\right)^{2}+2 \operatorname{Zr} 0\left(N_{t}-\tilde{N}_{t}\right)-5.528 \frac{\operatorname{EAr}_{0} f^{2}}{2}=0
$$

where $f=\left(v_{1}\right)_{\max }$ :

\footnotetext{
To simplify the reading and enhance comparisons, the following equations utilize the notations of the present paper.
} 
The above equations were evaluated numerically and the results are shown in Fig. 9 and Fig. 10.

Numata [10], using a different variant of the energy method and using different approximating functions for $\mathrm{v}$, obtained for shapes I to IV the following equations

$$
\begin{gathered}
f=\frac{\beta(2 Z)^{2} \rho_{0}}{\pi^{2}\left\{\tilde{\mathbb{N}}_{t}-\frac{(n+I)^{2} \pi^{2} E I}{(2 Z)^{2}}\right\}} \\
2 Z \lambda=22 \sqrt{\frac{\tilde{N}_{t}}{E I}}=(n+I) \sqrt{2} \pi
\end{gathered}
$$

and

$$
N_{t}-\tilde{N}_{t}=r_{0} Z\left\{-I+\sqrt{I+\frac{8 p_{0}^{2} \mu A(E I)^{5 / 2}}{r_{0} Z^{2} I\left(\tilde{N}_{t}\right)^{7 / 2}}}\right\}
$$

where the coefficients $n, \beta$, and $\mu$ are given in Table 5 .

TABLE 5. VALUES OF PARAMETERS

\begin{tabular}{|c|c|c|c|}
\hline $\begin{array}{c}\text { BuckIed } \\
\text { shape }\end{array}$ & $\mathrm{n}$ & $\beta$ & $\mu$ \\
\hline I & $I$ & 1.000 & 8.8857 \\
II & 2 & 0.2425 & 7.9367 \\
III & 3 & 0.1685 & 11.7867 \\
IV & 4 & 0.0977 & 16.3004 \\
\hline
\end{tabular}

The above equations were evaluated numerically and the results are shown in Figs. 9 through 12. For shapes I and II the agreement between the shown graphs is very close. However, for shapes III and IV the Numata results deviate noticeably from the exact ones and yield $\mathrm{T}_{\mathrm{L}}$ values which are about 10\% higher. 


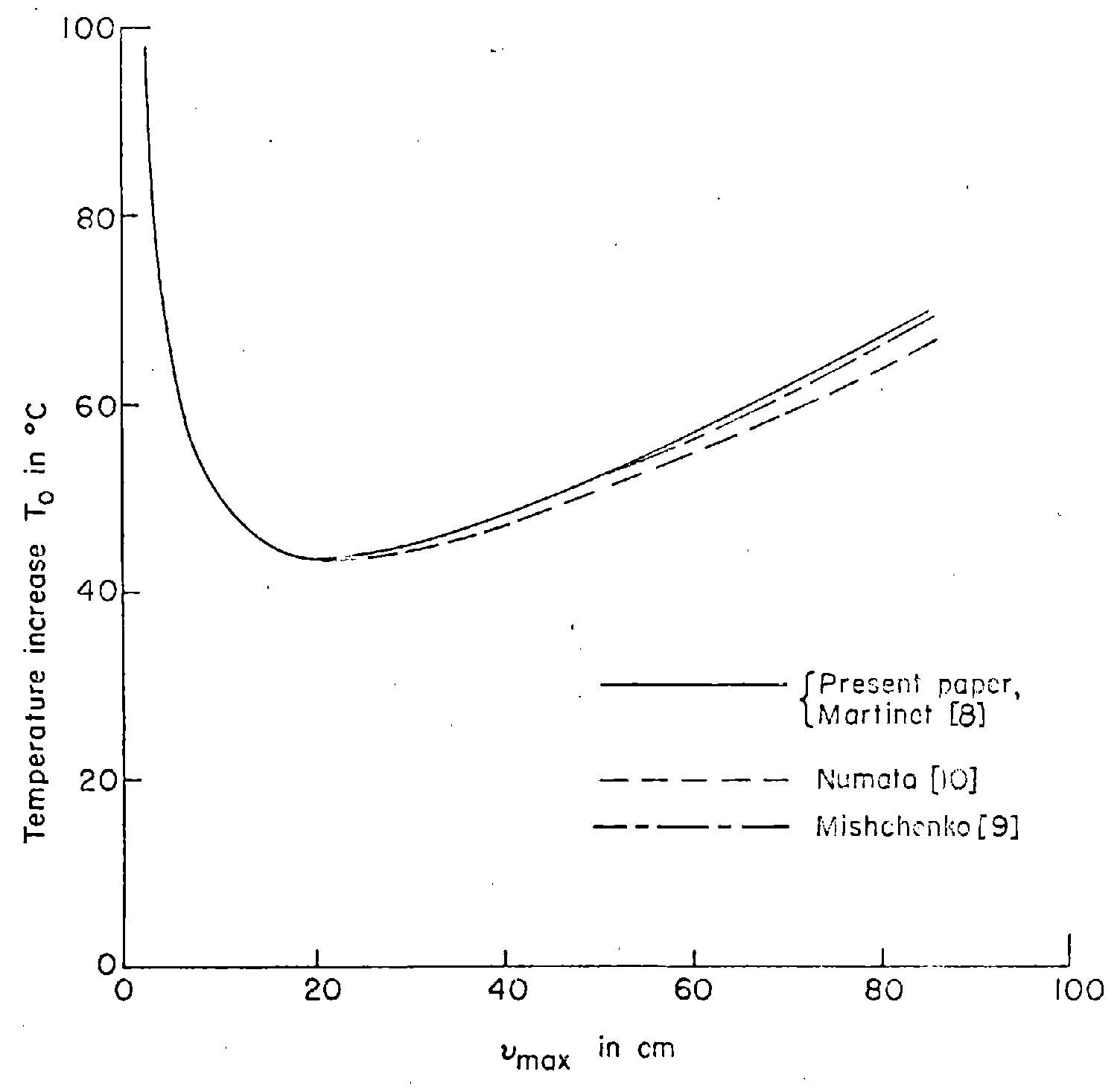

FIG. 9. COMPARISON OF POST-BUCKIING EQUILIBRIUM BRANCHES FOR SHAPE I BY MARTINET, MISHCHENKO, NUMATA, AND KERR. (The corresponding $\widetilde{\mathbb{N}}_{t}$-curves are, within the accuracy shown in Fig. 8 , essentially identical) 


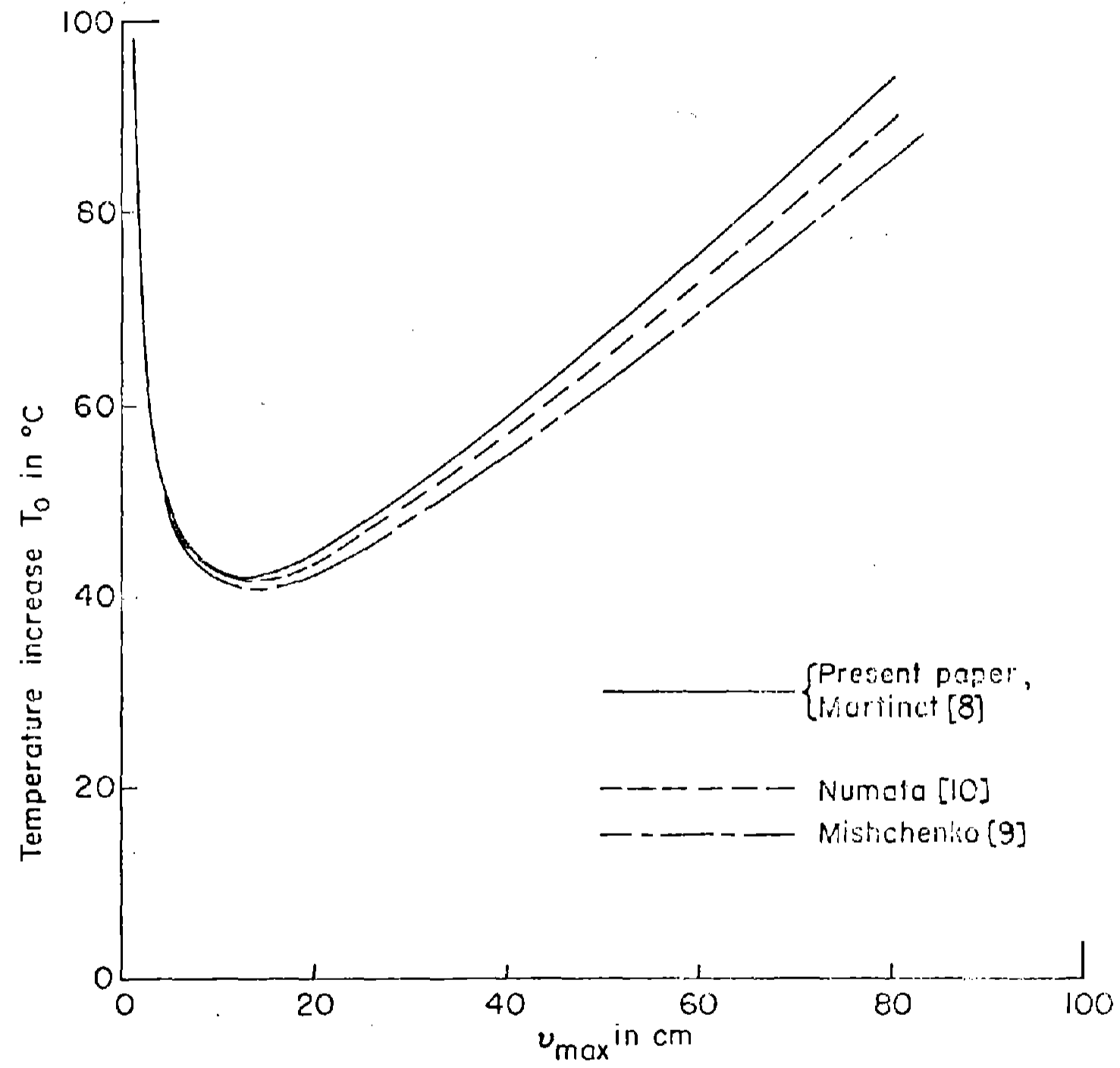

FIG. 10. COMPARISON OF POST-BUCKLING EQUILIBRTUM BRANCHES FOR SHAPE II BY MARTINET, MISHCHEINKO, NUMATA, AND KERR. (The corresponding $\widetilde{\mathbb{N}}_{t}$ curves are, within the accuracy shown in Fig. 8, essentially identical) 

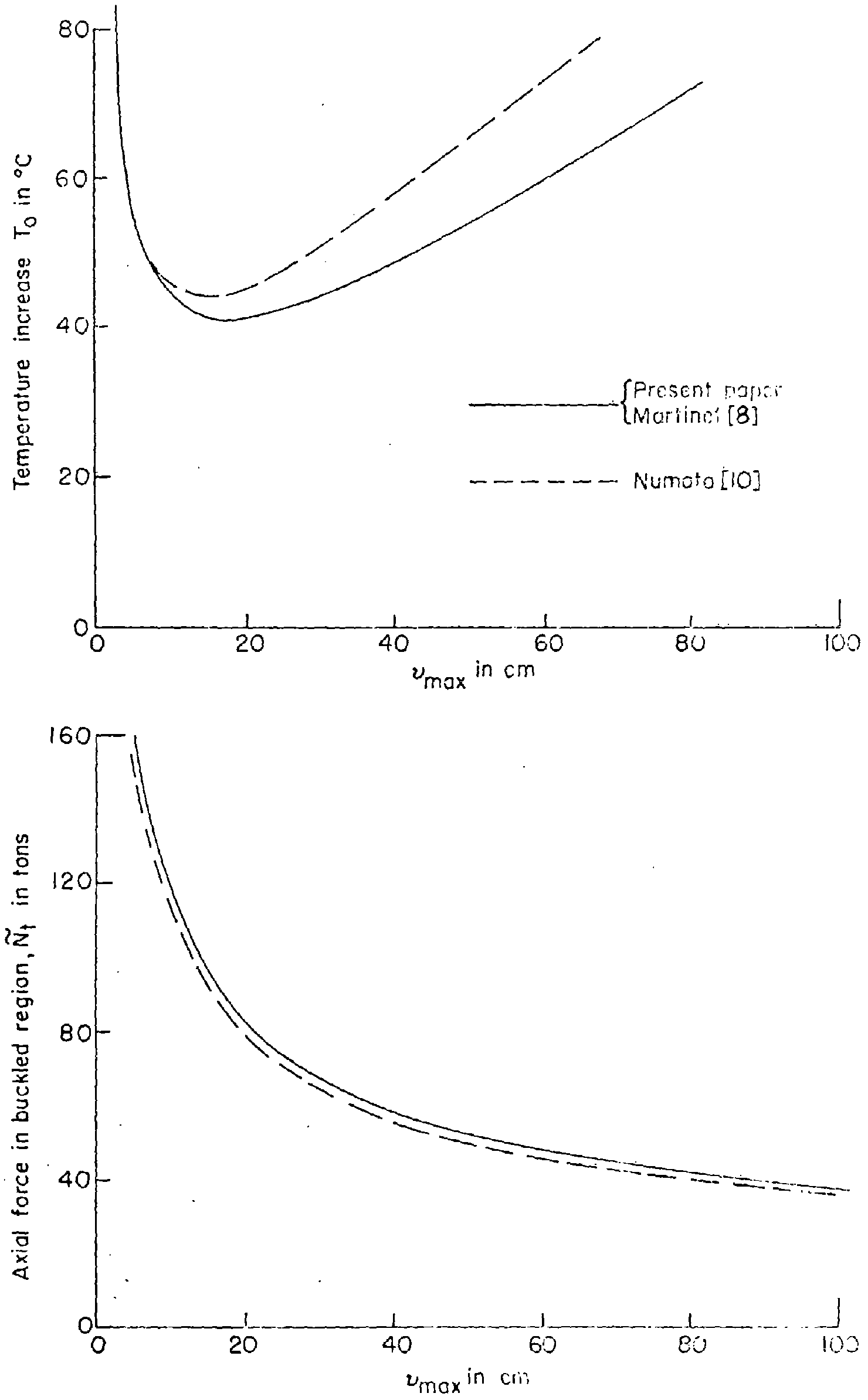

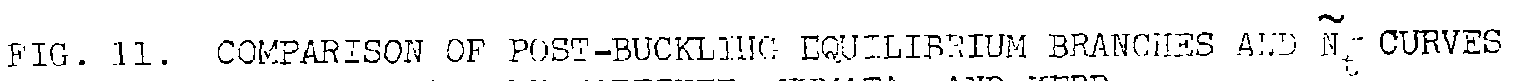
FOR SHAPE III BY HARTINET, NUMATA, AND KERR 

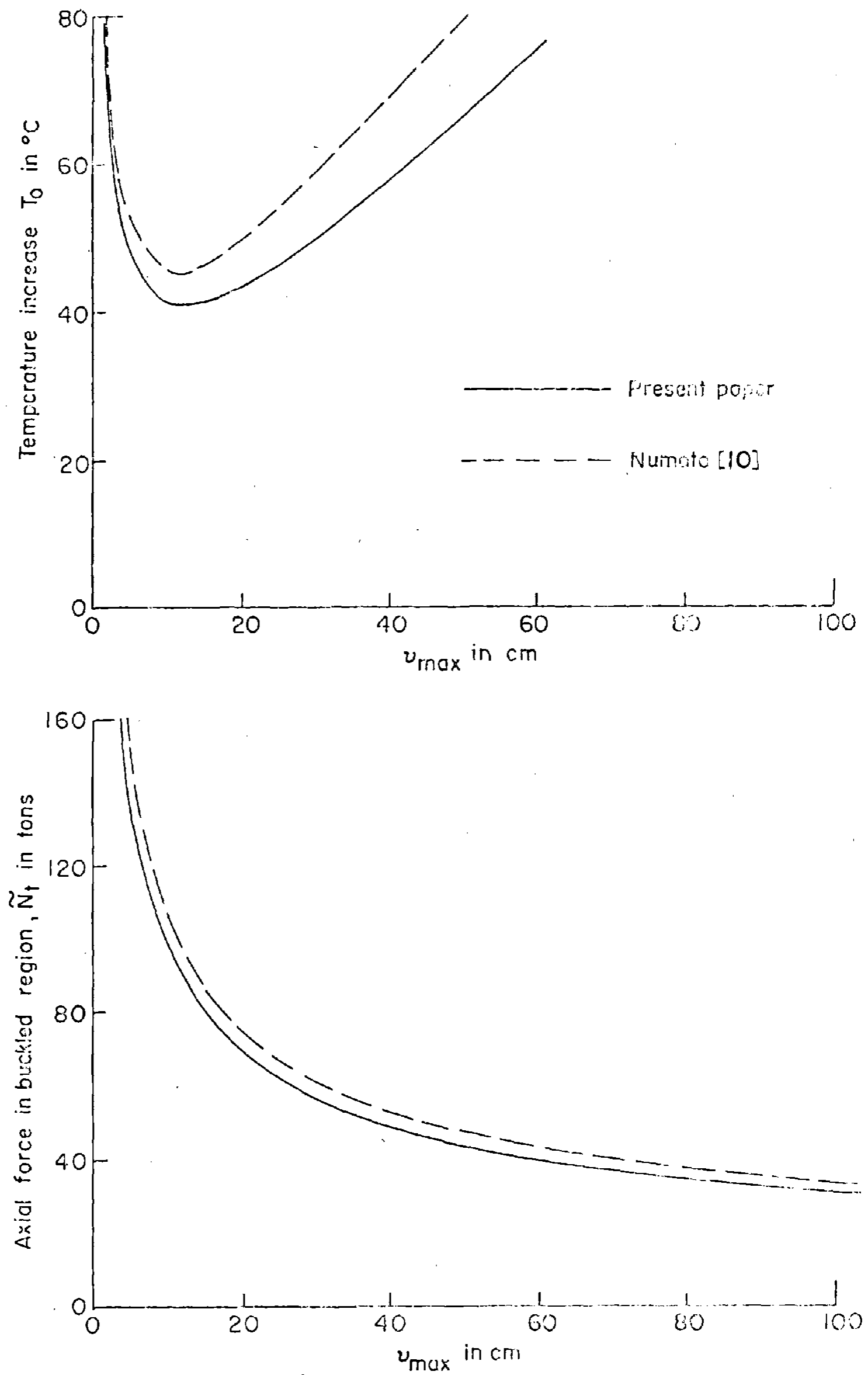

FIG. 12. COMPARISON OF POST-BUCKIING EQUILIBRIUM BRANCHES AND $\widetilde{\mathbb{N}}_{t}$-CURVES FOR SHAPE IV BY NUMATA AND KERR 
Note, however, that the above $\mathrm{T}_{\mathrm{L}}$-value is based on the used parameters and the made assumptions. So, for example, a lower lateral resistance $\rho_{0}$ caused by track maintenance activities will lower the $\mathrm{T}_{\mathrm{L}}$-value, whereas the effect of rail-tie fasteners which exhibit a torsional resistance will increase the range of safe temperature increases.

Note also that the assumption that the lateral resistance $\rho=\rho_{0}=$ const. was made in order to simplify the analyses. In actuality $\rho$ is of the shape shown in Fig. 3a. Thus, although the postbuckling equilibrium graphs shown in Fig. 8 indicate that the straight state is always stable (with decreasing stability for increasing $\mathrm{T}_{0}$ ), for an actual track there always exists a temperature increase $\mathrm{T}_{\mathrm{cr}}$ beyond which even the perfectly straight track may buckle ([3] Fig. 5). Also note that the assumption $\rho(x)=p_{0}$ is valid only for monotonically increasing deformations.

Another point to consider, is that actual tracks are not perfectly straight, but have small geometric imperfections. With minor modifications the formulations presented above are suitable also for the study of this problem. However, the resulting analyses are cumbersome and are also complicated by the uncertainty of the multitude of imperfection shapes encountered in an actual track.

The results obtained in references [3] (p. 36) and [5] suggest, however, that the effect of the relatively small lateral imperfections encountered in an actual track will be to decrease the value of $T_{\text {er }}$ without affecting noticeably the corresponding $\mathrm{T}_{\mathrm{L}}$-value. This in turn indicates the possibility that if the temperature increase in the rails of a track could be maintained (technically and economically) such that 
$T<T_{L}$, where $T_{I}$ is the value for the perfectly straight track discussed previously, then for engineering purposes there may be no need to determine the effect of lateral track imperfections on the safe temperature increase. 


\section{REFERENCES}

[1] Kerr, A. D., "The lateral buckling of railroad tracks due to constrained thermal expansions, - A Critical Survey" in Railroad Track Mechanics and Technology, Proceedings of a Symposium held at Princeton University April 21-23, 1975, A. D. Kerr Editor, Percamon Press, 1976.

[2] Birmann, F., "Neuere Messungen an Gleisen mit verschiedenen Unterschwellungen" (New measurements on tracks with different ties, ballast and subgrade, In German), Eisenbahntechnische Rundschau, Vol. 6, H. 7, 1957.

[3] Kerr, A. D., "The effect of lateral resistance on track buckling analyses," Rail Intermational, No. 1, 1976, pp. 30-38.

[4] Kerr, A. D., and El-Aini, Y., "Determination of admissible temperature increases to prevent vertical track buckling," Princeton University Research Report 75-SM-11, December 1975.

[5] Kerr, A. D., "Model study of vertical track buckling," High Speed Ground Transportation Journal, Vol. 7, 1973.

[6] Kerr, A. D., "On the derivation of well posed boundary value problems in structural mechanics," International joumal of Solids and Structures, Vol. 12, No. 1, 1976, pp. I-11.

[7] Novozhilov, V. V., "Teoria Uprugosti," Gos. Soyuz. Izd. Sudostroitelnoi Promyshlennosti, Leningrad, 1958. Translated into English as "Theory of Elasticity" by the Israel Program for Scientific Translations, Jerusalem, 1961, OTS 16-11401.

[8] Martinet, A., "Flambement des voies sans joints sur ballast et rails de grande longuer," (Buckling of the jointless track on ballast and very long rails, In French) Revvue Générale des Chemins de Fer, No. 10, 1936.

[9] Mishchenko, K. N., "Besstykovyi Relsovyi Fut," (The jointless railroad track, In Russian) Gos. Transp. Zh/D Izd., Moscow, 1950.

[10] Numata, M. "Buckling strength of continuous welded rail" Buzzetin Intermational Railway Congress Association, English Edition, January 1960.

[1]] Kerr, A. D., "On the stability of the railroad track in the vertical plane", Rail International, No. 2, 1974 , pp. 131-142. 
[12] Pershin, S. P., "Metody rascheta ustoichivosti besstykogo puti," (Methods for analyzing the buckling of a jointless railroad track, In Russian) Trudy MIIT, Vyp. 147, Moscow, 1962. 

APPENDIX:

REPORT OF INVENTIONS

\begin{abstract}
After a review of the work performed under this phase of the contract, it was determined that no technical innovation, discovery, or invention has been made. The work involved the development of an improved analysis for predicting the safe temperature, increase in the continuously welded rails of a railroad track, in order to prevent thermal track buckling.
\end{abstract}




\section{CONCLUSIONS AND RECOMMENDATIONS}

A study for the determination of the safe temperature increase in the rails of a straight track, to prevent lateral track buckling, was presented. The criterion used is based on the post-buckling equilibrium branches of the track. The range of the safe temperature increases was defined as

$$
\mathrm{T}_{0}<\mathrm{T}_{\mathrm{L}}
$$

where $\mathbb{T}_{\mathrm{L}}$ is the smallest value of the temperature rise at which a deformed state of equilibrium (thus, a buckled state) becomes possible.

It is shown that, contrary to the claims made in the literature, this problem can be formulated completely in terms of differential equations and the corresponding matching and boundary conditions.

It is also shown that the obtained non-linear formulation, because of a special analytical feature of the obtained differential equations, can be solved exactly, in closed form.

The obtained solutions for deformation shapes I to IV reveal that, for the track parameters used, the determined $\mathrm{T}_{\mathrm{L}}$ values are very close to each other. From the presented comparison of results for shapes I to IV and the following discussion it may be concluded that, for the determination of $\mathrm{T}_{\mathrm{L}}$, an analysis based on deformation shape II may be sufficient for engineering purposes.

According to Fig. 8, the obtained range of safe temperature increases for a track consisting of $115 \mathrm{lb} /$ yard rails which is attached to wooden ties by means of cut-spikes is

$$
\mathrm{T}_{0}<\mathrm{T}_{\mathrm{L}} \cong 42^{\circ} \mathrm{C}
$$


This deviation appears to be caused by the a priori assumption of the values for $\left(v_{1}\right)_{\max } /\left(v_{2}\right)_{\max }$ and the position of $\left(v_{2}\right)_{\max }$, which constitutes an additional analytical constraint on the solution. For example, whereas Numata stipulated for shape III

$$
\frac{\left(v_{1}\right)_{\max }}{\left(\mathrm{v}_{2}\right)_{\max }}=1.7 \quad \text { and } \quad \frac{\tau}{(\tau)_{\mathrm{v}_{2} \max }}=2
$$

the corresponding values which result from the exact solution, derived in the present paper, are

$$
\frac{\left(v_{1}\right)_{\max }}{\left(\mathrm{v}_{2}\right)_{\max }}=4.8 \quad \text { and } \quad \frac{\tau}{(\tau)_{\mathrm{v}_{2} \max }}=1.8
$$

Thus, according to the exact solution, the lateral displacements "damp out" more rapidly than assumed by Numata. This feature is even more pronounced for shape IV, as shown in Fig. 5.

Regarding the suitability of analytical methods for solving the thermal track buckling problem, it should be noted that the claim made by Mishchenko ([9] p. 63) and S. P. Pershin ([12] p. 42), that the differential equation approach is not suitable for a complete analysis* of the thermal track buckling problem, is not justified. As shown in the present paper the differential equation approach is capable of a complete determination of the post-buckling displacements and forces of the railroad track and thus for the determination of the range of safe temperature increases $\mathrm{T}_{\mathrm{O}}<\mathrm{T}_{\mathrm{L}}$

A track buckling analysis is referred to in the literature as complete when the drop of $\mathrm{N}_{t}$ to $\widetilde{\mathrm{N}}_{t}$ due to buckling is taken into consideration. As pointed out in [1], those numerous analyses, which do not talie into consideration this drop should not be considered as analyses of track buckling caused by constrained thermal expansions. 